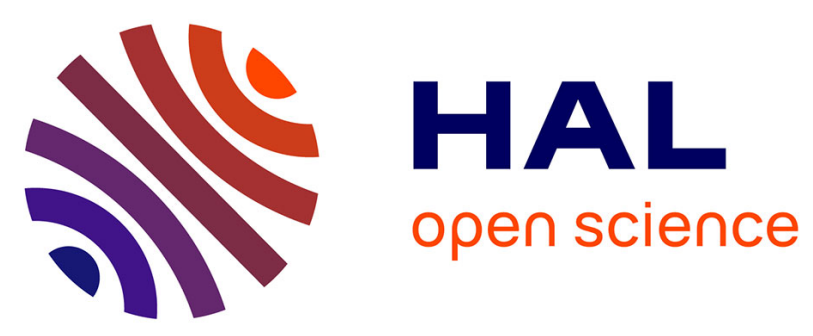

\title{
Mesoscale pore structure of a high-performance concrete by coupling focused ion beam/scanning electron microscopy and small angle X-ray scattering
}

Sébastien Brisard, Catherine Davy, Laurent Michot, David Troadec, Pierre Levitz

\section{To cite this version:}

Sébastien Brisard, Catherine Davy, Laurent Michot, David Troadec, Pierre Levitz. Mesoscale pore structure of a high-performance concrete by coupling focused ion beam/scanning electron microscopy and small angle X-ray scattering. Journal of the American Ceramic Society, 2019, 102 (5), pp.29052923. 10.1111/jace.16059 . hal-01904481

\section{HAL Id: hal-01904481 \\ https: / hal-enpc.archives-ouvertes.fr/hal-01904481}

Submitted on 6 Nov 2018

HAL is a multi-disciplinary open access archive for the deposit and dissemination of scientific research documents, whether they are published or not. The documents may come from teaching and research institutions in France or abroad, or from public or private research centers.
L'archive ouverte pluridisciplinaire HAL, est destinée au dépôt et à la diffusion de documents scientifiques de niveau recherche, publiés ou non, émanant des établissements d'enseignement et de recherche français ou étrangers, des laboratoires publics ou privés. 


\section{Mesoscale pore structure of a high-performance concrete by coupling focused ion beam/scanning electron microscopy and small angle $X$-ray scattering}

Sébastien Brisard, Catherine A. Davy, Laurent Michot, David Troadec, Pierre Levitz

This is the pre-peer reviewed version of the following article: "Mesoscale pore structure of a highperformance concrete by coupling focused ion beam/scanning electron microscopy and small angle X-ray scattering”, which has been published in final form at https://doi.org/10.1111/jace.16059. This article may be used for non-commercial purposes in accordance with Wiley Terms and Conditions for Use of Self-Archived Versions.

See Wiley's Self-Archiving Policy. 


\section{Mesoscale pore structure of a High Performance Concrete by coupling FIB/SEM and SAXS}

submitted to the Journal of the American Ceramic Society

S. Brisard ${ }^{1}$, C. A. Davy ${ }^{2}$, L. Michot ${ }^{3}$, D. Troadec ${ }^{4}$, P. Levitz ${ }^{3}$

May 31, 2018

*Corresponding author

1: Laboratoire Navier UMR CNRS 8205, and Ecole des Ponts, IFSTTAR, CNRS, UPE, F-77455 Marne-la-Vallée, France

2: Laboratoire de Mécanique de Lille (LML) FRE CNRS 3723, L2MGC EA 4114, Université de Cergy-Pontoise,

UCCS UMR CNRS 8181, F-59650 Villeneuve d'Ascq Cedex, France, and Centrale Lille, CS 20048, F-59651 Villeneuve d'Ascq Cedex, France E-mail: catherine.davy@centralelille.fr

3: Université Pierre et Marie Curie, Laboratoire Phenix UMR CNRS 8234, Paris, France

4: Institut d'Electronique, de Micro Electronique et de Nanotechnologie (IEMN), UMR CNRS 8520, BP60069, 59652 Villeneuve d'Ascq, France 


\section{Abstract (less than 200 words)}

This contribution couples (1) Small Angle X-ray Scattering (SAXS) experiments of a High Performance Concrete (HPC) at the millimetric scale, and (2) Focused Ion Beam/Scanning Electron Microscopy (FIB/SEM) of the cement paste of the HPC, with 10-20 nm voxel size. The aim is to improve the understanding of the 3D pore network of the HPC at the mesoscale (tens of $\mathrm{nm}$ ), which is relevant for fluid transport. The mature HPC is an industrial concrete, based on pure Portland CEMI cement, and planned for use as structural elements for deep underground nuclear waste storage.

SAXS patterns are computed from the 3D pore images given by FIB/SEM (volumes of 61-118 $\mu \mathrm{m}^{3}$ ). They are positively correlated to SAXS measurements (volumes of $5 \mathrm{~mm}^{3}$ ). Apart from correlations with FIB/SEM data, experimental SAXS allows to investigate a wider range of effects on the pore structure. These are mainly the HPC drying state, the presence of aggregates (by analyzing data on cement paste alone), and the use of PMMA resin impregnation.

Keywords High Performance Concrete (HPC); Focused Ion Beam/Scanning Electron Microscopy (FIB/SEM); Small Angle X-ray Scattering; mesoscale pore network 


\section{Contents}

1 Introduction 1

1.1 Industrial context . . . . . . . . . . . . . . . . . . . . . 1

1.2 Characterization of the pore network relevant to fluid transport . . . . . . 2

1.2.1 Usual indirect techniques . . . . . . . . . . . . . . . . . 2

1.2.2 Direct imaging techniques . . . . . . . . . . . . . . 3

1.2.3 Small-Angle X-ray Scattering (SAXS) . . . . . . . . . . . . . 4

1.3 Aims and scopes . . . . . . . . . . . . . . . . . . . 4

2 Experimental $\quad 5$

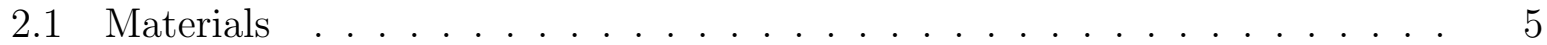

2.2 FIB/SEM Imaging $\ldots \ldots \ldots \ldots \ldots \ldots$

2.3 Small Angle X-Ray Scattering . . . . . . . . . . . . . . . . . . . . . 7

3 Numerical $\quad 8$

3.1 3D topological and morphological analysis . . . . . . . . . . . . . . 9

3.2 Estimating SAXS patterns from FIB-SEM images . . . . . . . . . . . 9

4 Results and analysis $\quad 10$

4.1 FIB/SEM imaging . . . . . . . . . . . . . . . . . . . . 10

4.2 Experimental SAXS f . . . . . . . . . . . . . . . . . . . . 13

4.2 .1 Reference state for the HPC . . . . . . . . . . . . . . . 13

4.2.2 Analysis of various parameters . . . . . . . . . . . . . . . . . 15

4.3 Correlations between FIB/SEM imaging and SAXS . . . . . . . . . . . . 16

$\begin{array}{llr}5 & \text { Concluding remarks } & 17\end{array}$

6 Appendix: morphological and topological tools for 3D porous media 19 


\section{Introduction}

\subsection{Industrial context}

In France, the long term repository of Intermediate Level or High Level and Long Lived nuclear waste (IL- or HL-LLW) is planned within a Callovo-Oxfordian (COx) claystone host rock, combined with an Engineered Barrier (EB). The structural elements of the EB are High Performance Concretes (HPCs), based on pure and composed Portland cements, coupled to a number of additional systems. For the safety assessment of the site, it is essential to understand the potential fluid transport through both the EB and the host rock. This requires a sufficient knowledge of the 3D pore network and of the microstructure of all materials and interfaces present in the EB. Whereas information about the host rock is currently increasing $[1,2,3]$, to our knowledge, much less is known regarding the characterization of the 3D pore network of HPCs. This is likely due to the following reasons.

Similarly to the host rock, the pore size distribution (PSD) of HPCs spans a wide range, from a few nanometers to tens of microns, with significant amounts in the nm to tens of $\mathrm{nm}$ range $[4,5,6]$. Generally, concrete is composed of non porous aggregates, assembled by a finely porous cement paste, whereas the so-called Interfacial Transition Zone (ITZ) is present between cement paste and aggregates. ITZ has a typical pore size on the order of microns to hundreds of microns $[7,8]$. However, these significant pore sizes alone do not explain either (1) the pore size distributions of HPC measured indirectly by Mercury Intrusion Porosimetry (with a diameter at $50 \%$ of the cumulative distribution $d_{50}$ on the order of 10-30 nm), or (2) the typically low permeability of the HPC (on the order of $10^{-18} \mathrm{~m}^{2}$ with gas [9] and $10^{-19} \mathrm{~m}^{2}$ with ethanol [6]). It is inferred that fluid flow through $\mathrm{HPC}$ is rather driven by the continuous paste volume surrounding the aggregates.

Comparatively to ITZ, and apart from isolated capillary pores with typical sizes of 
hundreds of nm, cement paste has a much finer porosity [10]. Cement hydrates (i.e. the socalled Calcium Aluminate and Silicate Hydrates C-A/S-H ${ }^{1}$ ) are the main solid components of cement paste, with variable phase properties [11]. The C-A/S-H exhibit inter-cluster pores with dimensions of 14-30 nm diameter, whereas intra-cluster pores are of 2-5 nm diameter [12]. These are thus all defined as mesopores by IUPAC [13].

\subsection{Characterization of the pore network relevant to fluid trans- port}

In such context, in order to characterize spatially the pore network of HPC, a number of methods exists, which are either indirect, or direct (imaging). The interest of indirect techniques is that they may be applied at the pluri-centimetric scale. The latter is considered a macroscopic scale, where the aggregates, the ITZ and the paste are present in sufficiently statistically representative amounts, when aiming to understand fluid transport [9]. Representativeness is generally considered achieved when the concrete sample size is at least three to five times that of the biggest concrete aggregate size.

\subsubsection{Usual indirect techniques}

Among indirect techniques available at the macroscopic scale, the use of sorption/desorption isotherms coupled to various models allows investigating bulk pluricentimetric concrete samples [14]. As a routine experiment, Mercury Intrusion Porosimetry (M.I.P.) is commonly used to assess a wide range of pores, from microns down to 4-6 $\mathrm{nm}$, depending on the maximum applied mercury pressure. However, this method is relevant at the centimetric scale, which is generally too small for concrete, but adequate for cement paste. Moreover, M.I.P. gives only a partial view of the pore structure [15], and relies on highly

\footnotetext{
${ }^{1}$ We use the standard cement abbreviations, where $\mathrm{C}$ stands for $\mathrm{CaO}$, S for $\mathrm{SiO}_{2}, \mathrm{~A}$ for $\mathrm{Al}_{2} \mathrm{O}_{3}$ and $\mathrm{F}$ for $\mathrm{Fe}_{2} \mathrm{O}_{3}$.
} 
simplifying assumptions regarding the material pore morphology. In particular, the pore network is assumed adequately represented by a set of independent circular cylindrical traversing pores of varying diameter. A similar problem is encountered with nitrogen adsorption, which provides indirect information on the pore system from hundreds of $\mathrm{nm}$ down to $0.35 \mathrm{~nm}[2]$. This method also relies on simplified assumptions about the geometry of the pore network. Furthermore, the sample is ground to powder before analysis, which makes its macroscopic representativeness questionable.

\subsubsection{Direct imaging techniques}

Direct imaging techniques provide a $2 \mathrm{D}$ or a $3 \mathrm{D}$ characterization of the solids and of the pore network, but the smaller the imaged pore size, the smaller the sample size.

For typical aggregate sizes of tens of $\mathrm{mm}$ [5], imaging can only be representative of macroscopic fluid transport if several volumes of tens of $\mathrm{mm}^{3}$ are considered. This can be achieved using either X-Ray micro-Computed Tomography (micro-CT) or 3D confocal microscopy [16], for voxel sizes of a few microns (down to a few hundreds of nm) [17]. Macroscopic representativeness is achieved in a statistical sense by multiplying the imaged sample volumes. However, these voxel sizes are not adapted to imaging the typical pore sizes of cement pastes.

Much smaller features ( $\mathrm{nm}$ to tens of $\mathrm{nm}$ ) are analyzed using electron microscopy techniques, e.g. Focused Ion Beam/Scanning Electron Microscopy (FIB/SEM) [18, 19, 20] or Scanning Transmission Electron Microscopy (STEM) [21], and X Ray ptychography [22]. Representativeness is only achieved at the scale of the cement paste or of the C-A/S-H [4], owing to significantly smaller samples sizes.

Cement paste imaging has a number of peculiarities, such as its fragility under the electron beam [23], the limited contrast between pores and solids (particularly with X-ray

micro-CT) $[17,20]$, and its great sensitivity to carbonation, particularly under moisture. 
Adequate strategies are generally devised to avoid these potential issues (e.g. freeze drying, an inert gas atmosphere above the samples, solvent replacement and/or resin impregnation) $[6,23,24,25,26]$.

\subsubsection{Small-Angle X-ray Scattering (SAXS)}

SAXS is an indirect experimental technique, which has been widely used to characterize particulate systems such as colloidal suspensions $[27,28,29,30]$. It is also well suited to probe the solid-pore interface of porous media, as well as the pores themselves, down to the sub nanometric scale $[30,31,32,33,34,35,36]$.

SAXS probes the spatial correlations of the electron density through the interactions of an incident X-ray beam with the sample. The measured SAXS pattern $I(q)$ relates the intensity $I$ of the scattered X-rays to the norm $q$ of the scattering vector ( $q$ is generally expressed in $\mathrm{nm}^{-1}$, or $\stackrel{\circ}{ }^{-1}$ ). Mathematically speaking, $I(q)$ is the Fourier transform of the autocorrelation function of the electron density [37].

For many systems, $I(q)$ follows a power-law in a limited $q$-range. The exponent and scaling coefficient of this power law can deliver valuable microstructural information. For instance, in the case of smooth pore/solid interfaces, e.g. at high $q$ (i.e. for $q$ ranging between $10^{-1}-1 \mathrm{~nm}^{-1}$ ), a so-called Porod regime is obtained, whereby $I(q)$ is proportional to $q^{-4}[31]$. For mass fractal systems (e.g. for suspensions and small $q$ ), $I(q)$ is proportional to $q^{-d}$ where $d$ is the fractal dimension [27]. For surface, interface or self-similar fractal systems (e.g. for porous solids, and higher $q$ ) [38], the scattered intensity $I(q)$ behaves as $q^{\left(-6-d_{s}\right)}$, where $d_{s}$ is the surface fractal dimension.

\section{$1.3 \quad$ Aims and scopes}

Our aim is to correlate the 3D pore structure of the cement paste of a HPC derived from FIB/SEM (volumes of $61-118 \mu \mathrm{m}^{3}$ ), with SAXS measurements obtained at a larger scale 
(samples of $5 \mathrm{~mm}^{3}$ ). Correlation is performed on $I(q)$ plots from SAXS experiments and from computations of the 3D FIB/SEM pore structure (i.e. from stacked and segmented binary images ${ }^{2}$ ).

Apart from providing data averaged on large volumes, experimental SAXS allows to investigate a wider range of effects on the mesocale pore structure than FIB/SEM. These are in particular the HPC drying state, the presence of aggregates, and the use of PMMA resin impregnation. SAXS experiments are also carried out on the sole mature cement paste, of identical pure Portland CEMI cement and water-to-cement $W / C$ ratio as the $\mathrm{HPC}$, in order to determine the effect of the presence of aggregates on $I(q)$ plots.

For FIB/SEM imaging, resin impregnation of HPC is performed using Poly Methyl MethAcrylate (PMMA) resin, which has high affinity for hydrophilic materials and a viscosity smaller than water prior to polymerization $[1,2,3,39]$. PMMA impregnation allows to image actual sections of the HPC (i.e. without parasitic effects of the imaged depth of the pores), and preserves the sample from carbonation.

\section{Experimental}

\subsection{Materials}

All mature concrete samples are taken from the same HPC as that studied in $[5,9,40,41]$. Its formulation is given in Table 3, with the calculation of the relative aggregate and paste volumes. After manufacturing and conditioning into pluricentimetric samples, the HPC is first matured for six months under water, and then either dried at $20^{\circ} \mathrm{C}$ and stepwisely down to $30 \%$ Relative Humidity $(R H)$, or at $80^{\circ} \mathrm{C}$ and stepwisely down to $12 \% R H$, for about five years. Sample mass is stable by less than $1 \%$ after this experiment. During

\footnotetext{
${ }^{2}$ In this contribution, 3D FIB/SEM binary image stacks are also called segmented images or segmented binary images.
} 
the drying process, carbonation is avoided by placing nitrogen gas regularly in the climatic chamber, mainly from $70 \% R H$ and below, where this phenomenon is reputed predominant.

As shown in Table 1 , the average porosity at the HPC scale $\phi=\frac{V_{\text {pores }}}{V_{H P C}}$ measured after 6 months maturation (by drying at $105^{\circ} \mathrm{C}$ and water saturation) is of $10.1 \%$ [5]. At the scale of the cement paste alone, porosity $\varphi:=\frac{V_{\text {pores }}}{V_{\text {paste }}}$ represents $45.7 \%$ (i.e. $10.1 \%$ over a paste volume $V_{\text {paste }}$ representing $22.2 \%$ of the concrete volume $V_{H P C}$ ).

One sample of each sort (HPC stewisely dried at 80 or $20^{\circ} \mathrm{C}$ ) are used for SAXS experiments, see 2.3 for their preparation technique. For FIB/SEM imaging, one HPC sample dried at $80^{\circ} \mathrm{C}$ and stepwisely down to $12 \% R H$ is impregnated with liquid MMA. PMMA is obtained by a thermal polymerization technique (using Benzoyle PerOxide -BPO- as a precursor to avoid forming nitrogen gas, and a temperature of $80^{\circ} \mathrm{C}$ ), used previously on COx claystone $[1,2,3]$.

Further, for SAXS experiments, cement paste samples are made using the same cement as the CEMI HPC, with the same $\mathrm{W} / \mathrm{C}$ ratio of 0.43 , and the same superplasticizer dosage [5]. The pastes are matured for at least six months under water, and gently dried at a constant temperature $T$ of $20^{\circ} \mathrm{C}$ and $43 \% R H$. Such $R H$ is obtained in the atmosphere above a salt saturated solution, unlike the $30 \% R H$. The latter was made available by using a dedicated climatic chamber [5, 41], which could not be accessed for the present study. During this drying process, carbonation is limited to the paste surface, hence samples for SAXS have been taken at a minimum distance of $5 \mathrm{~mm}$ from this surface.

\section{$2.2 \quad$ FIB/SEM Imaging}

Slice and View ${ }^{T M}$ is a software package of our FEI Strata DB 235 instrument (FEI Company). It allows automatic cutting of slices with the FIB and sequential recording of the freshly cut surface with the electron beam to produce FIB/SEM image stacks (or tomograms) $[1,2,3,42]$. For imaging purposes, a field emitting gun (FEG) is focused on the 
sample surface at an angle of $52^{\circ}$, with an acceleration voltage of $3 \mathrm{kV}$ and a current intensity of $1 \mathrm{nA}$. Both Secondary Electrons (SE) and BackScattered Electrons (BSE) are detected with an in lens detector. For slice cutting between two images, at a thickness of 10 or $20 \mathrm{~nm}$, a gallium liquid metal ion source (LMIS Ga+) is used at a voltage of $30 \mathrm{kV}$ and a current intensity of 1-3 nA. No damage of the sample is observed, which would otherwise result in vertical grooves on the sample freshly-cut surface.

The magnification is of $\mathrm{x} 35 \mathrm{k}$ to $\mathrm{x} 50 \mathrm{k}$, and the voxel size is described in Table 2 for all samples. In this contribution, only the sample dried at $80^{\circ} \mathrm{C}$ and stepwisely down to $12 \%$ $R H$ is imaged by FIB/SEM.

Four image series are purposely selected in the cement paste of the HPC and recorded, corresponding to volumes of 61.6-118.1 $\mu^{3}$ (Table 2). Numerical image computation (filtering, thresholding and quantification) is performed with the ImageJ software $[1,2,3]$. Our companion study, which focuses on the characterization of the pore network for fluid transport prediction [6], shows that the Otsu algorithm provides the most realistic pore segmentation for these images (from a purely visual point of view, among five other segmentation algorithms yielding similar pore space). The choice of the best suited segmentation algorithm is done using the same method in $[1,2,43,44]$. This $3 \mathrm{D}$ pore network provides adequate prediction of experimental macroscopic permeability, i.e. it is considered relevant to describe fluid transport through the HPC [6]. In the following, all FIB/SEM samples (cement1, cement2, cement3 and cement4) consist of image stacks segmented each with the Otsu algorithm.

\subsection{Small Angle X-Ray Scattering}

For experimental SAXS, the dry concrete and paste samples are of macroscopic size, cut with a diamond saw to prisms of $5 \mathrm{~mm}$ width, from either PMMA-impregnated or non impregnated matter (Table 3). After cutting, they are thinned down, by manual polishing 
with MP Piano (Struers) abrasive disks, down to a thickness of about 200 microns, resulting in volumes of about $5 \mathrm{~mm}^{3}$. In order to minimize artifacts on SAXS experimental data, the procedure is performed until mirror-like aspect, leaving only potential polishing grooves smaller than one micron.

SAXS experiments are carried out at the Swing beamline of the SOLEIL synchrotron radiation facility (Saint-Aubin, France). Measurements are made using a fixed energy of $12.0 \mathrm{keV}$ corresponding to a wavelength of $1.033 \AA$ ( $9.1003 \mathrm{~nm})$. Beam size applied to the sample is sub-millimetric. The sample position is adjusted visually to investigate the cement matrix in concrete samples. Acquisition times are adjusted to obtain the highest possible signal without detector saturation. They range between 10 and $300 \mathrm{~ms}$. In order to extend the investigated range of scattering vector modulus $q=(4 \pi / \lambda) \sin \theta$, where $2 \theta$ is the scattering angle and $\lambda$ the wavelength, three configurations are used for each sample. In the first configuration, the sample-to-detector distance is fixed at $1.6 \mathrm{~m}$, whereas the two other ones are based on a distance of $6.56 \mathrm{~m}$. The difference in these two latter configurations is the size of the beamstop used to prevent the direct X-ray beam from hitting the detector. The use of a very small beamstop allows reaching lower $q$ values. Under such conditions, the accessible $q$ range is $6.10^{-4} \AA^{-1} \leq q \leq 0.25 \AA^{-1}$ (i.e. $\left.6.10^{-3} \mathrm{~nm}^{-1} \leq q \leq 2.5 \mathrm{~nm}^{-1}\right)$. Scattering patterns are recorded on an AVIEX $170170 \mathrm{CCD}$ camera formed by four detectors and placed in a vacuum detection tunnel. After correction for the background, scattering patterns are radially averaged to obtain the scattering curves $I(q)$, which yields valid curves as the $2 \mathrm{D}$ experimental patterns are isotropic.

\section{Numerical}

This part describes different numerical methods applied to the FIB/SEM segmented images, for topological and morphological analysis, or for $I(q)$ reconstruction. 


\subsection{D topological and morphological analysis}

This part uses methods described in previous research [34, 45, 46, 47, 48]. The main elements are given in the Appendix (Section 6).

\subsection{Estimating SAXS patterns from FIB-SEM images}

It is well-known that the SAXS pattern is (up to a multiplicative constant) the power spectrum of the electron density $\rho_{\mathrm{e}}$. In other words, it is the Fourier transform of the autocorrelation function of $\rho_{\mathrm{e}}[49,37]$. For two-phase media, it is proportional to the power spectrum of the indicator function of one of the phases [49]. Since a binary 3D image of a microstructure is nothing but this indicator function, it is in principle possible to estimate the SAXS pattern from this image.

In the present case, we assume that the contrast between solid matrix and pores is the essential source of the SAXS pattern of hardened cement pastes, the heterogeneities within the solid matrix being neglected. This is possible owing to the preliminary segmentation of the original grayscale images [6]. In other words, from the perspective of SAXS, hardened cement pastes can be considered as two-phase media (pores and solids), and the SAXS pattern of the four FIB-SEM samples can be estimated from the power spectrum of their segmented 3D image stacks.

However, one should bear in mind that these samples are relatively small, which can induce significant finite-size artifacts in the estimate of the SAXS pattern $I(q)$ at small values of $q$ [36]. A classical remedy is the use of so-called window functions [50]. However, selection of the most appropriate window function and its parameters is problem-dependent. Another option is the symmetrization of the image. Both windowing and symmetrization can induce serious artifacts on the power spectrum that are difficult to quantify.

Recently, Moisan [51] introduced the "periodic plus smooth" decomposition of an image 
$u=p+s$, where $u$ denotes the initial image, $p$ and $s$ its periodic and smooth components. These components minimize a two-term cost function. The first term penalizes discontinuities at the boundary of the periodic component $p$, while the second term penalizes discontinuities at interior pixels of the smooth component $s$. The reader is referred to reference [51] for a mathematical definition of this cost function. Quite remarkably, the resulting optimization problem can be solved explicitly in the Fourier space. Besides, the solution can be implemented very efficiently by means of the Fast Fourier Transform (FFT).

As suggested by Moisan [51], the power spectrum of $u$ is then approximated by that of its periodic component $p$. Owing to its periodicity, the power spectrum of $p$ is not affected by finite-size effects at small $q$. The typical workflow for retrieving the SAXS pattern from a segmented 3D image stack is therefore as follows:

1. Compute Moisan's [51] "periodic plus smooth" decomposition $u=p+s$ of the binary image $u$.

2. Compute the 3D power spectrum $|\hat{p}|^{2}$ of the periodic component.

3. Compute the isotropic average of the power spectrum. Up to a multiplicative constant, this power spectrum should be close to the actual SAXS pattern of the same sample.

It should be noted that the decomposition algorithms proposed by Moisan [51] are formulated for 2D images. Extension to 3D images is straighthforward. The above workflow is illustrated in Figures 3 and 4 .

\section{Results and analysis}

\subsection{FIB/SEM imaging}

Most morphological and topological results are summarized in Table 4. 
Morphological characterization. As shown in Figs. 5 and 6, there are numerous isolated aggregates. The associated Betti numbers $\beta_{0, I}$ are high. However, the corresponding porosity of these isolated aggregates is rather low, between 0.8 and $1.4 \%$ (for an average expected porosity $\phi$ of $10.1 \%) .<l_{m}>$ and $<l_{p}>$ provide an estimation of porosity $\phi_{T}$ (Table 4). There is no significant difference when compared to direct measurement $\phi$ (Table 2 from $[6]$ ).

The two FIB/SEM samples cement3 and cement4 are obtained with a smaller and more isotropic voxel size than cement1 and cement2. They seem more homogeneously distributed than cement1 and cement2, with significantly greater numbers of vertices and branches $\alpha_{0, p}$ and $\alpha_{1, p}$. The specific surface area per unit volume $S_{v}$ is also significantly greater for cement3 and cement4 $\left(11.7\right.$ and $\left.12.8 \times 10^{6} \mathrm{~m}^{-3}\right)$ relatively to cement1 and cement2 $\left(7.38\right.$ and $\left.7.93 \times 10^{6} \mathrm{~m}^{-3}\right)$. This is attributed to a greater relative pore volume and a greater connectivity number $C_{t, p}$.

The Pore Size Distribution of the percolating pore network is shown in Fig. 8. The general trend is relatively the same. Samples cement3 and cement4 have a slightly lower average pore size $<d_{p}>$ than samples cement1 and cement2. For all samples, $<d_{p}>$ is of the same order of magnitude but lower than the average chord length $\left\langle l_{p}>\right.$. This result is in good agreement with the choice made to compute the P.S.D. As an illustrative example, let us consider an idealized slit pore of thickness $e$. Then we get $\left\langle l_{p}\right\rangle=2 e$ and $<d_{p}>=e$. The PSD computed from the FIB/SEM images are also in good agreement with former Mercury Intrusion Porosimetry (M.I.P.) results [5, 9, 52] and Fig. 8, with very close peak pore sizes, on the order of 20-30 nm diameter. Owing to their definition (as pore throats), they are smaller than $\left\langle d_{p}>\right.$ (Table 4$)$. 
Topological characterization. The chord distribution functions $f_{p}(r)$ and $f_{m}(r)$ are shown in Figure 7 . All of them exhibit an exponential tail at large distance, at a transition of around 150nm. For the solid network, these tails appear at shorter distance for cement3 and cement4. This is confirmed by the values of $\left\langle l_{m}>\right.$ which are smaller for cement3 and cement4 than for cement1 and cement2. Such an evolution is less pronounced for the pore network. The main origin of this observation is directly related to the more homogeneous microstructure of cement 3 and cement 4 compared to cement1 and cement2 (Fig. 6).

The retraction graphs of the percolating pore networks are shown in Figure 9. We retrieve the strong heterogeneity of samples cement1 and cement2 compared to cement3 and cement4. For all samples, the topological analysis shows a well connected percolating pore network structure. The connectivity number $C_{t, p}$ is well above 0.5 . This is generally encountered for highly connected networks [48]. The average coordination number around vertices ranges between 3.3 to 3.6. Interestingly enough, the probability density function of links around a connected vertex $P\left(N_{c, p}\right)$ does not exhibit an exponential evolution for cement1, cement2, cement 3 and cement 4 samples, although it is the case for a number of analyzed porous media made of clusters [53, 34, 47, 48].

Fractal analysis. Fig. 7 also shows that the relationships $f_{p}(r)$ and $f_{m}(r)$ may be fitted by power laws for $r$ ranging between 20 and $1000 \mathrm{~nm}$. However, when calculating the exponent of the power law for $f_{p}(r)$ or $f_{m}(r)$ on the same range $20-1000 \mathrm{~nm}$ for the four different FIB/SEM samples, a significant difference exists between the exponents for $f_{p}(r)$ and those for $f_{m}(r)$. For $f_{p}(r)$, the power law exponent ranges between -4.3 and -3.6, and for $f_{m}(r)$, this exponent ranges between -1.1 and -0.8 . This difference means that cement pastes imaged by FIB/SEM cannot be considered as surface fractal media. Otherwise, the exponents for $f_{p}(r)$ and $f_{m}(r)$ would be similar [38].

We have also studied the hypothesis of a mass fractal medium [47], whereby a power 
law $1 / r^{d_{m}-1}$ should be observed for $f_{p}(r)$ and an exponential tail for $f_{m}(r)$. With this assumption, a mass fractal dimension $d_{m}$ is obtained for $r$ below $100 \mathrm{~nm}$, with values ranging between 4.6 and 5.3. This is not within the usual range for such media [47].

Rather, the hypothesis of a long range Debye random medium [47] has been studied. It means that $f_{p}(r)$ and $f_{m}(r)$ are both represented by a given negative exponential tail above a few pixels, i.e. above $20 \mathrm{~nm}$ pore size here. The relationships $f_{p}(r)$ and $f_{m}(r)$ are written as:

$$
\begin{aligned}
& f_{p}(r) \propto \exp \left(-r / \lambda_{1}\right) \\
& f_{m}(r) \propto \exp \left(-r / \lambda_{2}\right)
\end{aligned}
$$

where $\lambda_{1}$ and $\lambda_{2}$ are constants characteristics of the medium under consideration. With this assumption, for our four FIB/SEM samples cement1, cement2, cement3 and cement4, $\lambda_{1}$ ranges between 71 and $111 \mathrm{~nm}$, with a median value of $87 \mathrm{~nm}$ (Fig. 10). This value (considered as an average pore size) is similar to, yet slightly bigger than the average chord length in the porous medium $<l_{p}>$ (Table 4). For $f_{m}(r), \lambda_{2}$ ranges between 277 and 405 $\mathrm{nm}$, with a median value of $344 \mathrm{~nm}$. Moreover, short distance deviations from linearity in Fig. 10, at $r$ below 150nm, may be attributed to rugosity or to polydispersity of pore sizes.

It is finally interpreted that cement pastes observed by FIB/SEM have a hierarchical microstructure (and not a fractal one), which displays significant pore amounts at different scales. It may be considered a long range Debye random medium [49, 47].

\subsection{Experimental SAXS}

\subsubsection{Reference state for the HPC}

For cement pastes, the pore network and the nanoscale structure of the C-A/S-H gel has first been investigated without disturbance (e.g. due to drying), by Allen et al. $[54,55,56$, 
57, 58] using Small Angle Neutron Scattering (SANS) experiments, prior to Ultra SmallAngle X-ray Scattering (USAXS) [59] and SAXS [60, 61]. SANS results have supported the theory [62] that two different morphologies of the C-A/S-H form during cement hydration, and accurate measurements of the surface area of cement pastes has been obtained with enhanced contrast using $\mathrm{D}_{2} \mathrm{O}$ (deuterium) $[63,64]$. However, pore size distributions of nanoscale C-A/S-H particles are determined based on a specific fractal model of the CA/S-H.

Further, SAXS has been used in [65] on pure hatrurite $\mathrm{C}_{3} \mathrm{~S}$ paste to investigate the fractal dimension $d_{s}$ of the pore/solid interface as a function of hydration time (1 to 385 days). Typical values for $d_{s}$ range between 2.33 (at 3 days) and 2.89 (at 385 days). For a two-year old Portland cement paste, Brisard et al. [30] determine a power law of $q^{-3.2}$ in the $q$ range of $10^{-3}-10^{-1} \mathrm{~nm}^{-1}$, corresponding to a fractal dimension $d_{s}$ of 2.8 , in good agreement with above-referenced results [65].

Complementarily, for a 1.5 year old Portland cement paste of water-to-cement ratio $\mathrm{W} / \mathrm{C}=0.35$, Brisard et al. [36] present experimental SAXS results with two distinct branches of the scattering pattern $\log (I(q))$, with a best fit by a power law of the form $q^{-3.2}$ for $q$ below $0.2 \mathrm{~nm}^{-1}$ and $q^{-2.5}$ for $q$ above $0.2 \mathrm{~nm}^{-1}$. An Appolonian packing of polydisperse spheres (which is a well defined geometrical construction) is proposed to represent the system. However, this provides a Porod regime at high $q$, and reproduces only the experimental $q^{-2.5}$ power law at low $q$.

Figure 11(a) displays the SAXS curve obtained for a reference concrete sample dried at $20^{\circ} \mathrm{C}$ and stepwisely down to $30 \% R H$ during 5 years, (with or without PMMA resin impregnation). At large $q$ the SAXS curve evolves as $q^{-4}$, according to Porod's law, whereas the low $q$ branch evolves as $q^{-2.9}$. Such an evolution has often been assigned in the literature to a fractal behavior. However, numerous recent experiments and simulations strongly suggest that such a concept is not well suited to describe Portland cement-based materials 
[66] (see also previous Sub-Section). In particular, no fractality exists when describing the C-A/S-H arrangement by inter-penetrating polydisperse solid spheres [66]. This geometry explains the C-A/S-H significant strength, which a fractal system cannot capture due to a too significant pore volume. Another instance when cement-based materials cannot be described as fractals is when changing from the homogeneous scale of the cement paste to the highly heterogeneous scale of the whole concrete (i.e. the paste combined to aggregates and ITZ). Qualifying Portland cement pastes (or HPCs) of hierarchical porous systems, with an array of pores at different distinct scales, seems more appropriate to account for their actual microstructure.

In Figure 11(a), the low $q$ evolution must then rather be interpreted as corresponding to a relatively dense arrangement of polydisperse objects (the so-called C-A/S-H clusters [4]), leading to the presence of pores that yield some contrast and consequently, X-ray scattering. The crossover region between the two regimes and the end of the Porod regime could be tentatively assigned to a characteristic size of objects in the sample that would then be around $15 \mathrm{~nm}\left(q \approx 4 \cdot 10^{-1} \mathrm{~nm}^{-1}\right)$.

\subsubsection{Analysis of various parameters}

SAXS is a well-adapted method for checking the possible influence of sample treatment on its microstructure. As an illustration, Figure 11(a) compares the SAXS curves obtained for similar HPC, one in its native state, the other treated by impregnation with PMMA. Both curves display very similar features. At low $q$, the curve corresponding to the impregnated sample is located slightly below that corresponding to the pristine sample, which can be interpreted as resulting from the lower contrast between solid and PMMA, compared to solid/air. In that regard, the fact that the two curves are superimposed at high $q$ values strongly suggests that in this regime, PMMA is not seen by X-rays. This could show that monomer molecules do not enter the very intimate structure of cement, i.e. it likely does 
not penetrate inside $\mathrm{C}-\mathrm{A} / \mathrm{S}-\mathrm{H}$ phases. In any case, for this particular sample, PMMA impregnation does not appear to impact the structure at the scale probed in the present SAXS study, i.e. between a few tenths of nm and one micron.

Potential differences between pure cement paste and cement paste in the concrete are probed by SAXS (Figure 11(b)). Differences between the two materials are rather marginal. Still, in the high $q$ region, the end of the Porod region seems to be better defined for cement paste, which may suggest that the smallest scattering units in this case are less polydisperse than those found in concrete. Furthermore, in the low $q$ region, the slope corresponding to cement paste appears slightly higher, which suggests that this material is more compact than the corresponding concrete.

Finally, the effect of drying intensity on the HPC is presented in Figure 12. The SAXS curves correspond to the reference $\mathrm{HPC}$ and to the $\mathrm{HPC}$ dried at $80^{\circ} \mathrm{C}$ and down to a relative humidity of $12 \%$ for five years. Significant changes appear to be linked to drying at $80^{\circ} \mathrm{C}$, especially in the low $q$ region. Indeed, drying at $80^{\circ} \mathrm{C}$ leads to a strong increase of the slope of SAXS curves up to 3.4, which reveals a much denser structure. Furthermore, in the very low $q$ region (below $2 \times 10^{-2} \mathrm{~nm}^{-1}$ ), the curves appear to slightly flatten, which may be due to the proximity of the beamstop. This feature will be discussed further in the following section where we compare SAXS results with FIB/SEM images.

\subsection{Correlations between FIB/SEM imaging and SAXS}

In Fig. 13, the $I(q)$ curves for FIB/SEM data (for volumes ranging between $61-118 \mu \mathrm{m}^{3}$ ) are compared to SAXS data on bigger samples (of about $5 \mathrm{~mm}^{3}$ ). They relate to the same $\mathrm{HPC}$, dried in identical conditions (at $80^{\circ} \mathrm{C}$ and stepwisely down to $12 \% R H$ ). In the $q$ range from $2 \times 10^{-2}$ to $2 \times 10^{-1} \mathrm{~nm}^{-1}$, an adequate fitting is obtained by a power law of the form $q^{-3.4}$ for both SAXS experiments and 3D simulations of $I(q)$ from FIB/SEM.

For $q$ bigger than $2 \times 10^{-1} \mathrm{~nm}^{-1}$, the $I(q)$ from FIB/SEM flatten and provide hardly 
anymore information. For $q$ smaller than $2 \times 10^{-2} \mathrm{~nm}^{-1}$, SAXS data are fitted by a power law of the form $q^{-2.1}$. Yet for the $I(q)$ calculated from FIB/SEM images, power law fittings range between $q^{-2.0}$ (for one sample out of four) and $q^{-1.4}$ (for three samples out of four). A partial match is therefore obtained. This suggests that the SAXS data are meaningful despite the proximity of the beamstop. In the opposite case, no correlation at all would be found with the FIB/SEM data. However, like in the case when $q$ is bigger than $2 \times 10^{-1}$ $\mathrm{nm}^{-1}$, for $q$ smaller than $2 \times 10^{-2} \mathrm{~nm}^{-1}$, the information provided by FIB/SEM data are not sufficiently representative of the cement paste at that scale. This corresponds roughly to object sizes on the order of $310 \mathrm{~nm}$ and bigger. FIB/SEM cannot be correlated with SAXS data for objects of $310 \mathrm{~nm}$ and bigger. However, such pore sizes are absent from the PSD distributions in Fig. 8, which display pore sizes up to about $200 \mathrm{~nm}$ only. It means that SAXS provides insights into bigger object sizes than those imaged by FIB/SEM. On the opposite, the topological and morphological information provided bu FIB/SEM is not available through SAXS. Both are complementary.

\section{Concluding remarks}

With FIB/SEM 3D pore structures, both topological and morphological analysis reveal a signifiant percolating pore volume of 10.2 to $17.7 \%$ at the scale of the cement paste, i.e. 2.3 to $3.9 \%$ at the macroscopic scale of the HPC, whereas $10.1 \%$ is expected on average (value obtained by the water saturation technique [5]). It means that $23-39 \%$ of the pore volume of the HPC is located in the cement paste and observed with FIB/SEM. This pore network has a good connectivity, with an average coordination number of the skeleton branches of the pore volume of 3.3-3.6.

Secondly, SAXS experiments show that PMMA impregnation does not affect significantly the $I(q)$ curves. The main difference is observed on HPC cement pastes, either 
dried at $20^{\circ} \mathrm{C}$ or at $80^{\circ} \mathrm{C}$. The latter presents a much denser structure than the former. Differences in $I(q)$ between bulk cement paste and cement paste in the HPC are limited. At high $q$, the smallest scattering units of bulk cement paste are less polydisperse than those found in concrete. In the low $q$ region, the slope corresponding to bulk cement paste appears slightly higher, which suggests that hydrated cement paste is more compact than the corresponding concrete.

Finally, SAXS data are compared to 3D simulations of $I(q)$ from FIB/SEM. In a $q$ range between $2 \times 10^{-2}$ to $2 \times 10^{-1} \mathrm{~nm}^{-1}$, a power law of the form $q^{-3.4}$ fits both SAXS data at the $m m^{3}$ scale and FIB/SEM simulations at the $\mu \mathrm{m}^{3}$ scale. For $q$ smaller than $2 \times 10^{-2} \mathrm{~nm}^{-1}$, similar fitting by a power law of the form $q^{-2.1}$ (for SAXS) or $q^{-2.0}$ (for FIB/SEM) is obtained with one FIB/SEM sample out of four. For the three other samples, a fitting by $q^{-1.4}$ is more adequate, meaning a divergence between the information provided by FIB/SEM and SAXS. FIB/SEM is expected to yield more limtied information on the paste structure than SAXS. The information corresponding to low $q$ (i.e. $q$ smaller than $2 \times 10^{-2} \mathrm{~nm}^{-1}$ or alternately object sizes on the order of $310 \mathrm{~nm}$ and bigger) are also missing from FIB/SEM pore volumes. This is confirmed by the PSD distributions determined from the FIB/SEM volumes. Bigger sample sizes would be necessary to complement this analysis.

In further research, smaller pore sizes i.e. pores on the order of 1-5 $\mathrm{nm}$ (and $q$ values on the order of 1-6 $\mathrm{nm}^{-1}$ ) will be investigated by direct imaging, and in particular by 2D or 3D STEM (Scanning Transmission Electron Microscopy) of the cement paste, and compared further to SAXS data. These pore sizes relate to the $q^{-4}$ power law of the $I(q)$ curves. Direct imaging by 3D confocal microscopy [16] will complement the analysis for pore sizes bigger than $300 \mathrm{~nm}$, in order to provide a "full" direct view of the multiscale pore structure of the HPC. 


\section{Acknowledgements}

We acknowledge funding by the inter-disciplinary challenge NEEDS MIPOR (Grand Défi Inter-Disciplinaire Nucléaire: Energie, Environnement, Déchets, Société - MIlieux POReux, funded by CNRS, CEA, EDF, ANDRA, AREVA, IRSN, BRGM, France) in 2015/2016, under the SAXSCOMPARE project label.

The SEM and TEM national facilities available at the Centre Commun de Microscopie de Lille (France) are supported by the Conseil Regional du Nord-Pas de Calais, and by the European Regional Development Fund (ERDF). Soleil is acknowledged for providing beamtime on the SWING beamline.

\section{Appendix: morphological and topological tools for $3 \mathrm{D}$ porous media}

The first tool used for morphological analysis of the 3D pore network is the determination of its two $\mu$-chord length distributions $[45,34,47]$. A chord is a segment belonging either to pore network $(\mathrm{p})$ or to solid matrix $(\mathrm{m})$ and having its two extremities on the interface. $\mu$-chords are obtained by tracing random and homogeneously distributed straight lines (rays) through a section or a $3 \mathrm{D}$ structure. The chord length distribution function is the probability distribution function (pdf) of having a chord length between $r$ and $r+d r$ belonging either to the pore network (the pdf $f_{p}(r)$ ) or to the solid matrix (the pdf $f_{m}(r)$ ). If a statistical isotropy of the material is assumed, the first moment of $f_{p}(r)$, noted $<l_{p}>$, is the average chord length in the pore network. Equivalently we note $\left\langle l_{m}>\right.$ the average chord length in the solid matrix. Using well-known stereological properties of statistical 
isotropic systems, the porosity $\phi$ and the specific surface area per unit volume $S_{v}$ write as:

$$
\begin{gathered}
\phi=\frac{<l_{p}>}{<l_{p}>+<l_{m}>} \\
S_{v}=\frac{4 \phi}{<l_{p}>}=\frac{4(1-\phi)}{<l_{m}>}
\end{gathered}
$$

Chord distribution functions probe local and semi-local geometry of the solid or of the pore network. $\left\langle l_{p}>\right.$ gives an estimation of the average size of the ill-defined "elementary pore".

As shown elsewhere $[34,53]$, the probability density functions $f_{p}(r)$ and $f_{m}(r)$ can be used as fingerprints of various classes of geometrical disorders. In particular, some authors consider cement-based materials as porous media with a fractal surface [45, 47]. In such case, the pore and solid chord distributions should both scale as:

$$
\begin{aligned}
& f_{p}(r) \propto 1 / r^{d_{s}-1} \\
& f_{m}(r) \propto 1 / r^{d_{s}-1}
\end{aligned}
$$

where $d_{s}$ is the fractal dimension of the internal material interface. This model will be tested in the following on the FIB/SEM images of the cement paste.

A second way to characterize the polydispersity of the pore network is to compute its Pore Size Distribution (P.S.D.). In disordered porous media such as cement pastes, it is difficult to give a unique definition of the elementary pore. In fact, the determination of the PSD depends on the experimental protocol used to measure it. Here, we choose to promote the bottlenecks which will be detected first, using standard mathematical morphology techniques. For this purpose, a structural element having $(2 n+1)^{3}$ voxels is considered at 
step $n$. Using this structural element, a closure followed by an opening of the solid network is performed in the $3 \mathrm{D}$ grid of voxels. The number of voxels belonging to the pore network and disappearing during this morphological operation is recorded at step $n$ and is used to compute the PSD. In the FIB/SEM image presented here, voxels are not cubic. In order to encompass this problem, we associate to the non cubic voxel, an average dimension equals to $(a 1 * a 2 * a 3)^{1 / 3}$ where $a 1, a 2, a 3$ are defined in Table 2 . This allows to scale the $\mathrm{x}$ axis of the normalized PSD.

The above P.S.D. algorithm has some similarity with the CPSD algorithm [1, 67]. With the latter, invasion starts by determining the largest sphere positionable inside the pore network, and the number of such spheres, in order to compute the relative pore volume at such sphere size. The sphere becomes smaller and smaller with the progression of the algorithm; at each sphere size, their number is determined and computed to provide a relative pore volume. This algorithm is available within the Beat plugin at ftp://ftp.empa.ch/pub/empa/outgoing/BeatsRamsch/lib and was used in earlier publications $[1,2,3,6]$.

The topological part of the analysis consists in determining the skeleton (or the retraction graph) of the 3D pore volumes given by the segmented FIB/SEM images, in order to quantify its long-range connectivity, contributing to transport [48]. The retraction graph is obtained by progressively narrowing the pore space starting from the internal surface. The difficulty is to reduce the numerical 3D pore volume to a simple graph made of interconnected branches having a start and an end at two defined vertexes (or vertices), while retaining the same topological properties at the local and global length-scales. In this contribution, we use the algorithm fully described in [46], instead of the Centerline Tree or the AutoSkeleton tools available in the Avizo software $\left(\mathrm{FEI}^{T M}\right)$, and used in earlier publications $[1,2,3,6]$. 
In this specific study, we will consider two different topological sets. The first set (I) gathers isolated pore aggregates which appear to be in large number, but contribute weakly to the total porosity. The second set $(\mathrm{P})$ is associated to the percolating pore network. For the four samples, we have computed the distribution of disconnected aggregates using Kopelman's algorithm. For each sample, there is one and only one very big cluster spreading in 3D to the boundaries of the reconstruction. Whether an intrusion is performed along $\vec{x}, \vec{y}$, or $\vec{z}$, the same single percolating pore network is obtained. This cluster represents between 90 to $95 \%$ of the porosity. In this paper, we mainly consider the topological properties related to this percolating pore network. For the associated graph, the number of vertices $\alpha_{0, p}$ and the number of branches $\alpha_{1, p}$ allow to compute the connectivity number $C_{t, p}[48]$ as

$$
C_{t, p}=-\left(\alpha_{0, p}-\alpha_{1, p}\right) / \alpha_{0, p}
$$

$C_{t, p}$ is an intensive parameter related to the number of irreducible paths per vertex (or vertice). For a highly connected pore network, $C_{t, p}$ is positive. However, whenever a great number of isolated vertices is characterized, $\alpha_{0}$ dominates in the right part of Eq. 7 , and $C T$ is then negative, ranging between 0 and -1 .

As detailed in $[47,48]$, the average coordination number around vertices is written as:

$$
<N_{c, p}>=2 \times\left(\alpha_{1, p} / \alpha_{0, p}\right)=2\left(C_{t, p}+1\right)
$$

$<N_{c, p}>$ is the first moment of the probability density function $P\left(N_{c, p}\right)$, which is the probability density function of links around a connected vertex. 


\section{References}

[1] Y. Song, C. A. Davy, D. Troadec, A.-M. Blanchenet, F. Skoczylas, J. Talandier, and J.-C. Robinet. Characterization of the fine pore structure of COx claystone. Marine and Petroleum Geology, 65:63-82, 2015.

[2] Y. Song, C. A. Davy, D. Troadec, P. Bertier, and F. Skoczylas. Understanding fluid transport through claystones from their 3D nanoscopic pore network. Microporous and Mesoporous Materials, 228:64-85, 2016.

[3] Y. Song, C. A. Davy, and D. Troadec. Gas Breakthrough Pressure (GBP) through claystones: correlation with FIB/SEM imaging of the pore volume. Oil and Gas Science and Technology (OGST), 71:51-77, 2016.

[4] K. Scrivener and A. Nonat. Hydration of cementitious materials, present and future. Cement and Concrete Research, 41:651-665, 2011.

[5] F. Brue, C. A. Davy, F. Skoczylas, N. Burlion, and X. Bourbon. Effect of temperature on the water retention properties of two high performance concretes. Cement and Concrete Research, 42:384-396, 2012.

[6] Y. Song, C. A. Davy, and D. Troadec. Understanding fluid transport through a high performance concrete (HPC) from its 3D mesoscale pore network. Cement and Concrete Research, under revision, 2017.

[7] J. A. Larbi. Microstructure of the interfacial zone around aggregate particles in concrete. Heron, 38(1):1-69, 1993.

[8] K. Scrivener and K. M. Nemati. The percolation of pore space in the cement paste/aggregate interfacial zone of concrete. Cement and Concrete Research, 26(1):3540, 1996. 
[9] W. Chen, J. Liu, F. Brue, F. Skoczylas, C. A. Davy, X. Bourbon, and J. Talandier. Water retention and gas relative permeability of two industrial concretes. Cement and Concrete Research, 42(7):1001-1013, 2012.

[10] P. K Mehta and P. J. M. Monteiro. Concrete: microstructure, properties, and materials. 2006 .

[11] H. F. W. Taylor. Cement Chemistry. 2nd Edition, Thomas Telford, London, 1997.

[12] P.J. McDonald, V. Rodin, and A. Valori. Characterisation of intra- and inter-C-S-H gel pore water in white cement based on an analysis of NMR signal amplitudes as a function of water content. Cement and Concrete Research, 40(12):1656-1663, 2010.

[13] M. Thommes, K. Kaneko, A. V. Neimark, J. P. Olivier, F. Rodriguez-Reinoso, J. Rouquerol, and K. S.W. Sing. Physisorption of gases, with special reference to the evaluation of surface area and pore size distribution. 2015.

[14] V. Baroghel-Bouny. Water vapour sorption experiments on hardened cementitious materials - Part I: Essential tool for analysis of hygral behaviour and its relation to pore structure. Cement and Concrete Research, 37:414-437, 2007.

[15] S. Diamond. Mercury porosimetry: an inappropriate method for the measurement of pore size distributions in cement-based materials. Cement and Concrete Research, 30(10):1517-1525, 2000.

[16] M. H. N. Yio, M. J. Mac, H. S. Wong, and N. R. Buenfeld. 3d imaging of cement-based materials at submicron resolution by combining laser scanning confocal microscopy with serial sectioning. Journal of Microscopy, 258(2):151-169, 2015.

[17] E. Gallucci, K. Scrivener, A. Groso, M. Stampanoni, and G. Margaritondo. 3D exper- 
imental investigation of the microstructure of cement pastes using synchrotron X-ray microtomography (microCT). Cement and Concrete Research, 37:360-368, 2007.

[18] L. Holzer, P. Gasser, and B. Münch. Quantification of capillary pores and hadley grains in cement paste using FIB-nanotomography, pages 509-516. Dordrecht: Springer, 2006.

[19] L. Holzer, B. Münch, A. Leemann, and P. Gasser. Quantification of capillary porosity in cement paste using high resolution 3D-microscopy: Potential and limitations of FIB-nanotomography. Quebec: RILEM, pp. 247 (electronic media), 2006.

[20] Holzer L. and Cantoni M. Nanofabrication using Focused Ion and Electron Beams. In edited by Utke I., Moshkalev S. and Russell P. (Oxford University Press, Oxford, New York), pages 410-435, 2012.

[21] E. Boehm-Courjault, J. E. Rossen, and K. Scrivener. Composition and morphology of C-S-H in C3S pastes hydrated by water/isopropanol mixes using electron microscopy. In Proceedings of the 15th Euroseminar on Microscopy Applied to Building Materials (EMABM), Delft, The Netherlands, pages 279-286, 2015.

[22] S. Bae, R. Taylor, D. Shapiro, P. Denes, J. Joseph, R. Celestre, S. Marchesini, H. Padmore, T. Tyliszczak, T. Warwick, D. Kilcoyne, P. Levitz, and P.J.M. Monteiro. Soft X-ray Ptychographic Imaging and Morphological Quantification of Calcium Silicate Hydrates (C-S-H). Journal of the American Ceramic Society, 98 (12):4090-4095, 2015.

[23] C. Rössler, J. Stark, F. Steiniger, and W. Tichelaar. Limited-Dose Electron Microscopy Reveals the Crystallinity of Fibrous C-S-H Phases. Journal of the American Ceramic Society, 89(2):627-632, 2006.

[24] Lorenz Holzer, Beat Münch, Marta Rizzi, Roger Wepf, Paul Marschall, and Thomas 
Graule. 3D-microstructure analysis of hydrated bentonite with cryo-stabilized pore water. Applied Clay Science, 47(3):330-342, 2010.

[25] C. Rössler, F. Steiniger, and H. M. Ludwig. Characterization of C-S-H and C-A$\mathrm{S}-\mathrm{H}$ phases by electron microscopy imaging, diffraction and energy dispersive X-ray spectroscopy. Journal of the American Ceramic Society, 100:17331742, 2017.

[26] J. Zhang and G. W. Scherer. Comparison of methods for arresting hydration of cement. Cement and Concrete Research, 41:"1024-1036", 2011.

[27] M. S. Diallo, C. J. Glinka, W. A. III Goddard, and J. H. Jr Johnson. Characterization of nanoparticles and colloids in aquatic systems 1. Small angle neutron scattering investigations of Suwannee River fulvic acid aggreggates in aqueous solutions. Journal of Nanoparticle Research (Springer), 7:435-448, 2007.

[28] L. Michot, I. Bihannic, S. Maddi, S. S. Funari, C. Baravian, P. Levitz, and P. Davidson. Liquid-crystalline aqueous clay suspensions. Proceedings of the National Academy of Sciences of the United States of America (PNAS), doi:10.1073/pnas.0605201103, 2006.

[29] C. Rivière, C. Wilhelm, F. Cousin, V. Dupuis, F. Gazeau, and R. Perzynski. Internal structure of magnetic endosomes. European Physics Journal E, 22:1-10, 2007.

[30] S. Brisard, R. S. Shae, I. Bihannic, L. Michot, P. Guttmann, J. Thieme, G. Schneider, Monteiro P. J. M., and P. Levitz. Morphological quantification of hierarchical geomaterials by X-ray nano-CT bridges the gap from nano to micro length scales. American Mineralogist, 97:480-483, 2012.

[31] D. Pearson and A. J. Allen. A study of ultrafine porosity in hydrated cements using small angle neutron scattering. Journal of Materials Science, 20:303-315, 1985. 
[32] P. Levitz, G. Ehret, S. K. Sinha, and J. M. Drake. Porous Vycor glass: The microstructure as probed by electron microscopy, direct energy transfer, small - angle scattering, and molecular adsorption. The Journal of Chemicals Physics, 95:6151-, 1991.

[33] M. Y. Lin, S. K. Sinha, J. M. Drake, X.-I. Wu, P. Thiyagarajan, and H. B. Stanley. Study of phase separation of a binary fluid mixture in confined geometry. Physical Review Letters, 72(14):2207, 1994.

[34] Levitz P. Statistical modeling of Pore network. Copyright WILEY-VCH Verlag GmbH, 69469 Weinheirn (Federal Republic of Germany), 2002.

[35] A. P. Radlinski, M. A. Ioannidis, A. L. Hinde, M. Hainbuchner, M. Baron, H. Rauch, and S. R. Kline. Angström-to-millimeter characterization of sedimentary rock microstructure. Journal of Colloidal and Interface Science, 274:607-612, 2004.

[36] Sébastien Brisard and Pierre Levitz. Small-angle scattering of dense, polydisperse granular porous media: Computation free of size effects. Physical Review E, 87(1):013305, 2013.

[37] G. Porod. General theory. In O. Glatter and O. Kratky, editors, Small angle X-ray scattering, chapter 2, pages 17-51. Academic Press, 1982.

[38] P. Levitz. Off-lattice reconstruction of porous media: critical evaluation, geometrical confinement and molecular transport. Advances in Colloid and Interface Science, 76-77:71-106, 1998.

[39] J.C. Robinet, P. Sardini, D. Coelho, J.C. Parneix, D. Prêt, S. Sammartino, E. Boller, and S. Altmann. Effects of mineral distribution at mesoscopic scale on solute diffusion in a clay-rich rock: Example of the Callovo-Oxfordian mudstone (Bure, France). Water Resources Research, 48, 2012. 
[40] Y. Zhang, C. A. Davy, G. Tricot, C. Albert-Mercier, N. Henry, P. Bertier, F. Cazaux, D. Damidot, and X. Bourbon. On shrinkage and structure changes of pure and blended Portland cements and concretes. Journal of the American Ceramic Society, doi: 10.1111/jace.14915, 2017.

[41] F. Brue, C. A. Davy, F. Skoczylas, N. Burlion, and X. Bourbon. Five year drying of high performance concretes: effects of temperature and cement-type on shrinkage. Cement and Concrete Research, 99:70-85, 2017.

[42] D.A. Matthijs De Winter, C.T.W.M. Schneijdenberg, M.N. Lebbink, B. Lich, A. J . Verkleij, M.R. Drury, and B.M. Humbel. Tomography of insulating biological and geological materials using focused ion beam (FIB) sectioning and low-kV BSE imaging. Journal of Microscopy, 233:372383, 2009.

[43] Lukas M Keller, Lorenz Holzer, Roger Wepf, and Philippe Gasser. 3D geometry and topology of pore pathways in Opalinus clay: Implications for mass transport. Applied Clay Science, 52:85-95, 2011.

[44] Lukas M Keller, Philipp Schuetz, Rolf Erni, Marta D Rossell, Falk Lucas, Miriam Lucas, Philippe Gasser, and Lorenz Holzer. Characterization of multi-scale microstructural features in Opalinus clay. Microporous and Mesoporous Materials, 170:83-94, 2013.

[45] I. Cousin, P. Levitz, and A. Bruand. Three-dimensional analysis of a loamy-clay soil using pore and solid chord distributions. European Journal of Soil Science, 47:439-452, 1996.

[46] L. Pothuaud, P. Porion, E. Lespessailles, C. L. Benhamou, and P. Levitz. A new method for three-dimensional skeleton graph analysis of porous media: application to trabecular bone microarchitecture. Journal of Microscopy, 199:149-161, 2000. 
[47] P. Levitz. Toolbox for 3D imaging and modeling of porous media: Relationship with transport properties. Cement and Concrete Research, 37:351-359, 2007.

[48] P. Levitz, V. Tariel, M. Stampanoni, and E. Gallucci. Topology of evolving pore networks. Eur. Phys. J. Appl. Phys., 60:24202, 2012.

[49] P. Debye, H. R. Anderson Jr., and H. Brumberger. Scattering by an inhomogeneous solid. II. The correlation function and its application. Journal of Applied Physics, 28(6):679-683, 1957.

[50] F.J. Harris. On the use of windows for harmonic analysis with the discrete Fourier transform. Proceedings of the IEEE, 66(1):51-83, 1978.

[51] Lionel Moisan. Periodic plus smooth image decomposition. Journal of Mathematical Imaging and Vision, 39(2):161-179, 2011.

[52] S. M'Jahad, Y. Zhang, C. A. Davy, F. Skoczylas, and X. Bourbon. Water retention and gas migration of two high performance concretes after diffuse damage. Journal of Materials in Civil Engineering (ASCE), http://dx.doi.org/10.1061/(ASCE)MT.19435533.0001028:'A4014008-1 to A4014008-112014', 2015.

[53] P. Levitz and D. Tchoubar. From chord distribution to small angle scattering. Journal de Physique I, 2:771-790, 1992.

[54] A. J. Allen, C. G. Windsor, V. Rainey, D. Pearson, D. D. Double, and N. McN. Alford. A small-angle neutron scattering study of cement porosities. Journal of Physics D: Applied Physics, 15(9):1817-1834, 1982.

[55] D. Pearson and A. J. Allen. A study of ultrafine porosity in hydrated cements using small-angle neutron-scattering. Journal of Materials Science, 20(1):303-315, 1985. 
[56] A. J. Allen, R. C. Oberthur, D. Pearson, P. Schofield, and C. R. Wilding. Development of the fine porosity and gel structure of hydrating cement systems. Philosophical Magazine B, 56(3):263-288, 1987.

[57] A. J. Allen. Time-resolved phenomena in cements, clays and porous rocks. Journal of Applied Crystallography, 24(Part 5):624-634, 1991.

[58] J. J. Thomas, H. M. Jennings, and A. J. Allen. The surface area of cement paste as measured by neutron scattering: evidence for two C-S-H morphologies. Cement and Concrete Research, 28(6):897-905, 1998.

[59] Andrew J. Allen and Richard A. Livingston. Relationship between differences in silica fume additives and fine-scale microstructural evolution in cement based materials. Advanced Cement Based Materials, 8(3-4):118-131, 1998.

[60] Andrew J. Allen and Jeffrey J. Thomas. Analysis of C-S-H gel and cement paste by small-angle neutron scattering. Cement and Concrete Research, 37(3):319-324, 2007. Cementitious Materials as model porous media: Nanostructure and Transport processes - July 2005, Centro Monte Verita, Switzerland.

[61] A. J. Allen, J. J. Thomas, and H. M. Jennings. Composition and density of nanoscale calcium-silicate-hydrate in cement. Nature Materials, 6(4):311-316, 2007.

[62] P. D. Tennis and H. M. Jennings. A model for two types of csh in the microstructure of portland cement pastes. Cem. Concr. Res., 30(6):855-863, 2000.

[63] Jeffrey J. Thomas, Hamlin M. Jennings, and Andrew J. Allen. Determination of the neutron scattering contrast of hydrated Portland cement paste using H2O/D2O exchange. Advanced Cement Based Materials, 7(3-4):119-122, 1998. 
[64] Jeffrey J. Thomas, Jeffrey J. Chen, Andrew J. Allen, and Hamlin M. Jennings. Effects of decalcification on the microstructure and surface area of cement and tricalcium silicate pastes. Cement and Concrete Research, 34(12):2297-2307, 2004.

[65] R. Maggion. Etude de l'Evolution Microtexturale de Pâtes de Silicate Tricalcique Hydraté. PhD thesis, Orléans University, France, 1992.

[66] K. Ioannidou, K. J. Krakowiak, M. Bauchy, C. G. Hoover, E. Masoero, S. Yip, F. J. Ulm, P. Levitz, R. J.-M. Pellenq, and E. Del Gado. Mesoscale texture of cement hydrates. Proceedings of the National Academy of Sciences of the United States of America (PNAS), doi/10.1073/pnas.1520487113, 2016.

[67] Beat Münch and Lorenz Holzer. Contradicting geometrical concepts in pore size analysis attained with electron microscopy and mercury intrusion. Journal of the American Ceramic Society, 91(12):4059-4067, 2008.

[68] G. Camps. Etude des interactions chemo-mécaniques pour la simulation du cycle de vie d'un élément de stockage en béton. PhD thesis, LMDC, Université de Toulouse, France, 2008. 


\section{List of Tables}

1 Formulation of the industrial HPC based on CEMI cement used in this study and in [5], of water-to-cement ratio $(\mathrm{W} / \mathrm{C})=0.43$, with solid density data from [68], for the calculation of the cement paste and aggregate volumes for $1 \mathrm{~m}^{3}$ concrete (right column). The HPC cure is of six months at $20^{\circ} \mathrm{C}$ under lime-saturated water, followed by drying either at $20^{\circ} \mathrm{C}$ and stepwisely down to $30 \%$ Relative Humidity $(R H)$, or at $80^{\circ} \mathrm{C}$ and stepwisely down to $12 \% R H$, for about five years $[41] \ldots \ldots \ldots \ldots$

2 Characteristics of the FIB/SEM samples selected in the cement paste of a pure Portland HPC at the mesoscale, cured for six months under water followed by stepwisely drying at $80^{\circ} \mathrm{C}$ down to $12 \% R H$, for about five years

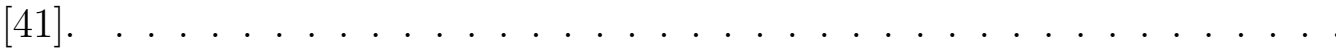

3 Main features of the samples used for SAXS experiments. These are either from the same HPC batch as in [41] and for FIB/SEM imaging, or corresponding to a cement paste especially made for this study, and cured as indicated above. . . . . . . . . . . . . . . . .

4 Results of the morphologic and topological analysis of FIB/SEM image stacks cement1, cement2, cement3, cement4 of the cement paste of a HPC, based on $[53,34,47,48]$. The last four lines of this table provide information on the percolating pore network only. . . . . . . . . . . . . . . 


\begin{tabular}{|c|c|c|c|c|c|}
\hline Component & Nature & Source & $\begin{array}{l}\text { Amount } \\
\left(\mathrm{kg} / \mathrm{m}^{3}\right. \\
\text { concrete })\end{array}$ & $\begin{array}{c}\text { Solid } \\
\text { density } \\
\left(\mathrm{kg} / \mathrm{m}^{3}\right)\end{array}$ & $\begin{array}{c}\text { Relative } \\
\text { volume (vol \% } \\
\text { per } \mathrm{m}^{3} \text { concrete) }\end{array}$ \\
\hline Sand & $\begin{array}{l}\text { Limestone } \\
(0-4 \mathrm{~mm})\end{array}$ & $\begin{array}{c}\text { Boulonnais } \\
\text { quarry, France }\end{array}$ & 858 & 2650 & 32.4 \\
\hline Gravel & $\begin{array}{l}\text { Limestone } \\
(5-12 \mathrm{~mm})\end{array}$ & $\begin{array}{c}\text { Boulonnais } \\
\text { quarry, France }\end{array}$ & 945 & 2670 & 35.4 \\
\hline Cement & $\begin{array}{c}\text { CEMI 52.5R } \\
\text { PM ES }\end{array}$ & $\begin{array}{c}\text { Lafarge, } \\
\text { France }\end{array}$ & 400 & 3160 & \\
\hline Super-plasticizer & Glenium 27 & BASF & 10 & 1050 & $\begin{array}{c}32.2 \text { (before } \\
\text { hydration) }\end{array}$ \\
\hline Water & - & tap & 171 & 1000 & \\
\hline $\begin{array}{c}\text { Average } \\
\text { porosity }(\%)\end{array}$ & & & & & $\begin{array}{l}1.5 \text { before } \\
\text { hydration } \\
10.1 \text { after } \\
\text { hydration }\end{array}$ \\
\hline
\end{tabular}

Table 1: Formulation of the industrial HPC based on CEMI cement used in this study and in [5], of water-to-cement ratio $(\mathrm{W} / \mathrm{C})=0.43$, with solid density data from [68], for the calculation of the cement paste and aggregate volumes for $1 \mathrm{~m}^{3}$ concrete (right column). The HPC cure is of six months at $20^{\circ} \mathrm{C}$ under lime-saturated water, followed by drying either at $20^{\circ} \mathrm{C}$ and stepwisely down to $30 \%$ Relative Humidity $(R H)$, or at $80^{\circ} \mathrm{C}$ and stepwisely down to $12 \% R H$, for about five years [41]. 


\begin{tabular}{|c|c|c|c|c|}
\hline $\begin{array}{c}\text { Sample } \\
\text { n. }\end{array}$ & $\begin{array}{c}\text { Voxel size } \\
a_{1} \times a_{2} \times a 3 \\
\left(\mathrm{~nm}^{3}\right)\end{array}$ & $\begin{array}{l}\text { Sample } \\
\text { size } \\
\left(\mu \mathrm{m}^{3}\right)\end{array}$ & $\begin{array}{c}\text { Total } \\
\text { porosity } \\
\text { - Otsu } \phi(\%)\end{array}$ & $\begin{array}{c}\text { Total porosity } \\
\left(\mu \text { chords) } \phi_{T}\right. \\
(\%)\end{array}$ \\
\hline cement 1 & $\begin{array}{c}5.94 \times 7.54 \times 20 \\
=895.7\end{array}$ & $\begin{array}{c}5.58 \times 4.35 \times 4 \\
=97.1\end{array}$ & 10.30 & 10.25 \\
\hline cement2 & $\begin{array}{c}5.94 \times 7.54 \times 20 \\
=895.7\end{array}$ & $\begin{array}{c}3.98 \times 3.87 \times 4 \\
=61.6\end{array}$ & 11.84 & 11.83 \\
\hline cement3 & $\begin{array}{c}5.94 \times 7.54 \times 10 \\
=447.9\end{array}$ & $\begin{array}{c}5.38 \times 7.06 \times 3.11 \\
=118.1\end{array}$ & 16.58 & 16.65 \\
\hline cement 4 & $\begin{array}{c}5.93 \times 7.54 \times 10 \\
=447.1\end{array}$ & $\begin{array}{c}5.40 \times 7.32 \times 2.88 \\
=113.8\end{array}$ & 17.75 & 17.75 \\
\hline $\begin{array}{c}\text { Average } \\
\pm \text { max } \\
\text { deviation }\end{array}$ & $\begin{array}{c}671.6 \\
\pm 224.3\end{array}$ & $\begin{array}{c}97.7 \\
\pm 44.3\end{array}$ & $\begin{array}{c}14.12 \\
\pm 3.8\end{array}$ & $\begin{array}{l}14.12 \\
\pm 3.9\end{array}$ \\
\hline
\end{tabular}

Table 2: Characteristics of the FIB/SEM samples selected in the cement paste of a pure Portland HPC at the mesoscale, cured for six months under water followed by stepwisely drying at $80^{\circ} \mathrm{C}$ down to $12 \% R H$, for about five years [41]. 


\begin{tabular}{|c|c|c|c|}
\hline Sample n.1 & Sample type & Preparation mode & Sample size $\left(\mathrm{mm}^{3}\right)$ \\
\hline I & CEMI HPC & $\begin{array}{r}\text { dried at } 20^{\circ} \mathrm{C} \text { and stepwisely } \\
\text { down to } 30 \% R H\end{array}$ & $5 \times 5 \times 0.2 \pm 0.09$ \\
II & CEMI HPC & $\begin{array}{r}\text { impregnated with PMMA } \\
\text { dried at } 20^{\circ} \mathrm{C} \text { and stepwisely } \\
\text { down to } 30 \% R H\end{array}$ & $5 \times 5 \times 0.2 \pm 0.09$ \\
III & CEMI Cement paste & $\begin{array}{r}\text { impregnated with PMMA } \\
\text { dried at } 20^{\circ} \mathrm{C} \text { and stepwisely } \\
\text { down to } 43 \% R H\end{array}$ & $5 \times 5 \times 0.2 \pm 0.09$ \\
\hline IV & CEMI HPC & $\begin{array}{r}\text { non impregnated with PMMA } \\
\text { dried at } 80^{\circ} \mathrm{C} \text { and stepwisely } \\
\text { down to } 12 \% R H\end{array}$ & $5 \times 5 \times 0.2 \pm 0.09$ \\
& impregnated with PMMA & \\
\hline
\end{tabular}

Table 3: Main features of the samples used for SAXS experiments. These are either from the same HPC batch as in [41] and for FIB/SEM imaging, or corresponding to a cement paste especially made for this study, and cured as indicated above. 


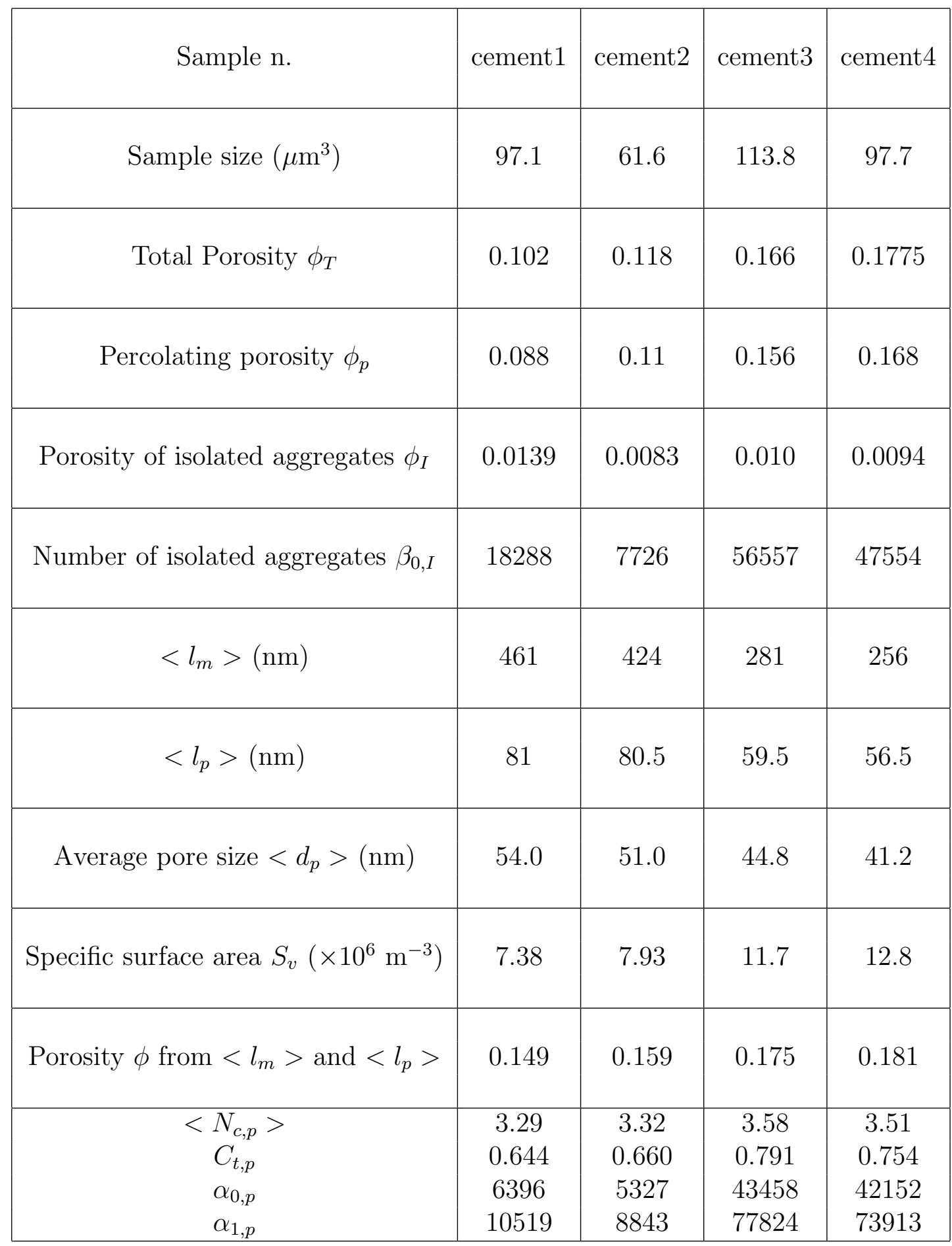

Table 4: Results of the morphologic and topological analysis of FIB/SEM image stacks cement1, cement2, cement3, cement4 of the cement paste of a HPC, based on [53,34, 47, 48]. The last four lines of this table provide information on the percolating pore network only. 


\section{List of Figures}

1 Principle of the FIB/SEM Slice and View ${ }^{T M}$ procedure. . . . . . . . . . .

2 FIB/SEM images, before and after segmentation by the Otsu algorithm, of CEMI HPC for sample (a,b): cement1; (c,d): cement2, (e,f): cement3 and

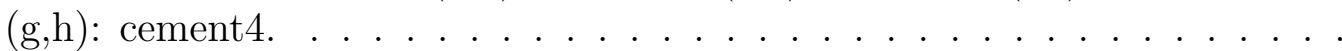

3 'Periodic plus smooth' decomposition of a segmented image of the FIB/SEM stack cement3. The figure shows a slice $u$ of the initial image (left), as well as its periodic (middle) and smooth (right) components $p$ and $s$. For the sake of illustration, this decomposition is computed in $2 \mathrm{D}$, not $3 \mathrm{D}$, on a small, $256 \times 256$, region of interest. Besides, the four quadrants of the image have been swapped, in order to emphasize the lack of periodicity of the initial image, as indicated by the jumps along the horizontal and vertical median axes. These jumps are smeared in the periodic component $p$, while the smooth component $s$ is essentially constant far from the boundaries. The same color scale is used for all three images. . . . . . . . . . . . .

$42 \mathrm{D}$ power spectrum of the periodic component $p$ shown in Figure 3. Computing the isotropic average of this image finally leads to the curves shown in Figure 13. . . . . . . . . . . . . . . . . . . . .

5 Isolated clusters from the FIB/SEM segmented images of CEMI HPC for sample (a): cement1; (b): cement2; (c): cement3; and (d): cement4. . . . . Isolated vertexes from the retraction graphs of the FIB/SEM segmented images of CEMI HPC for sample (a): cement1; (b): cement2; (c): cement3; and $(\mathrm{d}):$ cement $\ldots \ldots \ldots \ldots \ldots$

7 Chord length distributions (in a log-log diagram), obtained from the FIB/SEM segmented images of a CEMI HPC, on samples cement1, cement2, cement3 and cement4.

8 Pore size distributions in volume, obtained from the FIB/SEM segmented images of CEMI HPC, and compared to M.I.P. on concretes of different batches, from $[5,41 ?, 52] \ldots \ldots \ldots \ldots \ldots$

9 Retraction graphs from the FIB/SEM segmented images of CEMI HPC for sample (a): cement1; (b): cement2; (c): cement3; and (d): cement4. . . . .

10 Chord length distributions (in a log-linear diagram), obtained from the FIB/SEM segmented images of a CEMI HPC, on samples cement1, cement2, cement3 and cement4: (a): raw data; (b): interpolation in the least squares sense on the same 20-1000nm radius $r$ range for $f_{p}(r)$ and $f_{m}(r) \ldots \ldots$.

11 Experimental SAXS results on samples II and III: HPC dried at $20^{\circ} \mathrm{C}$ and stepwisely down to $30 \% R H$ for five years, (a): with and without PMMA resin-impregnation; (b): $\mathrm{HPC}$ dried at $20^{\circ} \mathrm{C}$ and stepwisely down to $30 \%$ $R H$ for five years, compared to pure Portland mature cement paste dried at $20^{\circ} \mathrm{C}$ and $43 \% R H$. In (b), both samples are not impregnated with PMMA. 
12 Experimental SAXS results on Samples II and IV: HPC dried at either $20^{\circ} \mathrm{C}$ and stepwisely down to $30 \% R H$ for five years, or at $80^{\circ} \mathrm{C}$ and stepwisely down to $12 \% R H$ for five years. Both samples are impregnated with PMMA. 50

13 Comparison of $I(q)$ plots given by experimental SAXS $\left(80^{\circ} \mathrm{C} ; 12 \% R H\right)$ or by $3 \mathrm{D}$ numerical computations from FIB/SEM segmented images (Samples cement1, cement2, cement3 and cement4). . . . . . . . . . . 51 


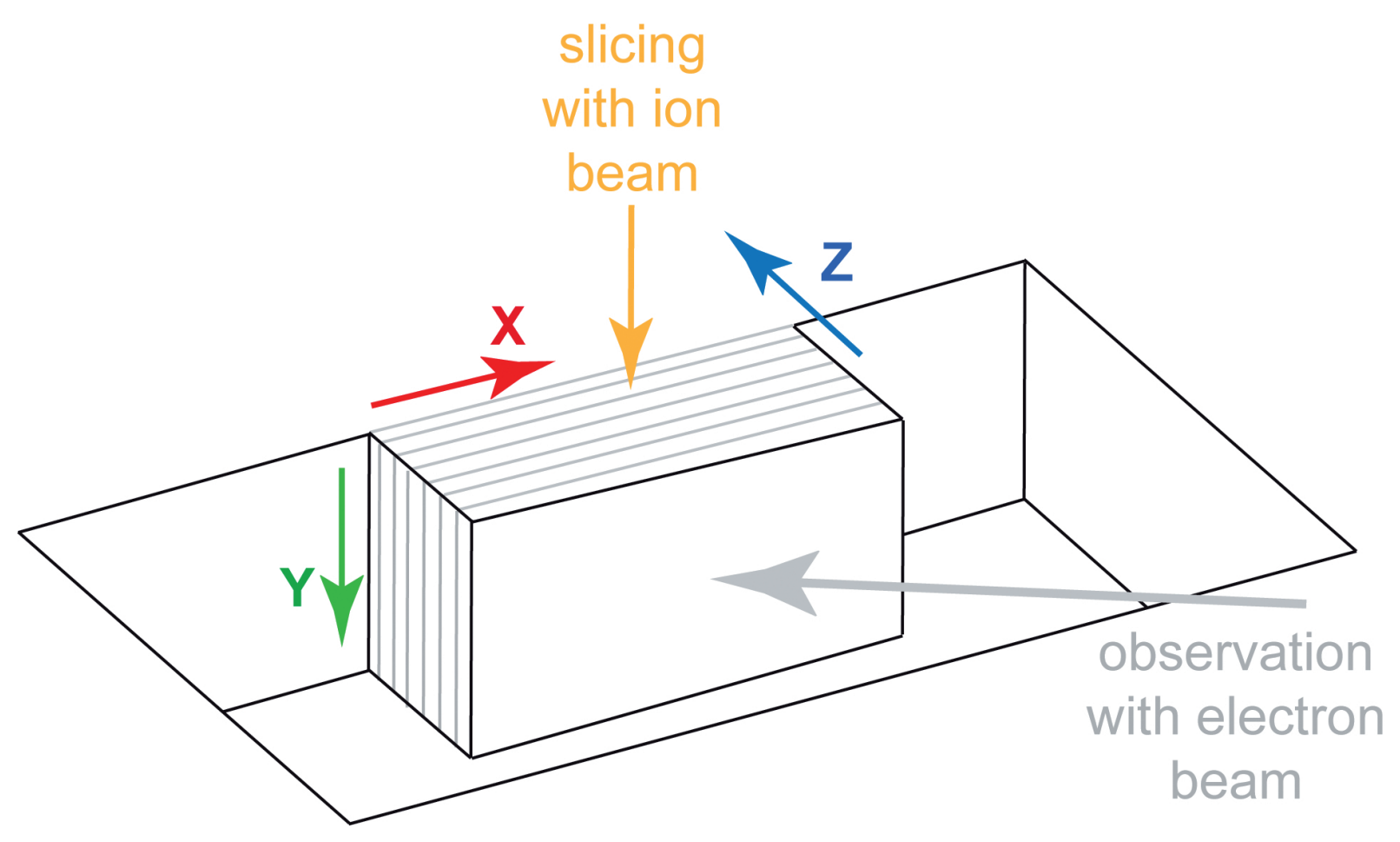

Figure 1: Principle of the FIB/SEM Slice and View ${ }^{T M}$ procedure. 


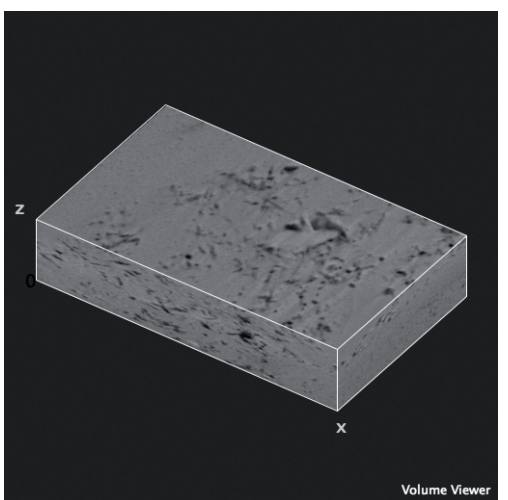

(a)

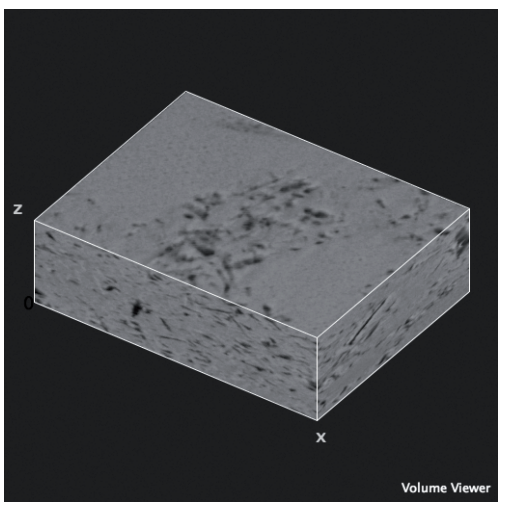

(c)

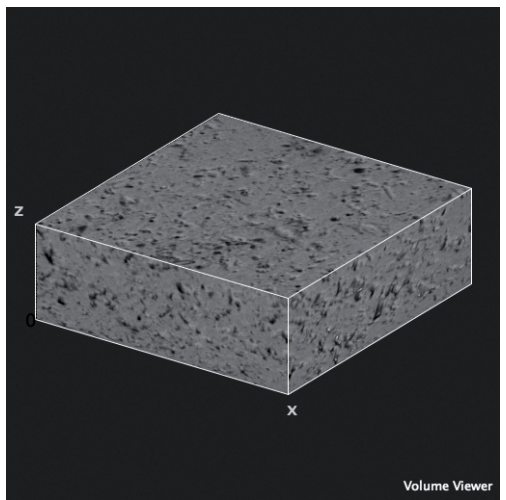

(e)

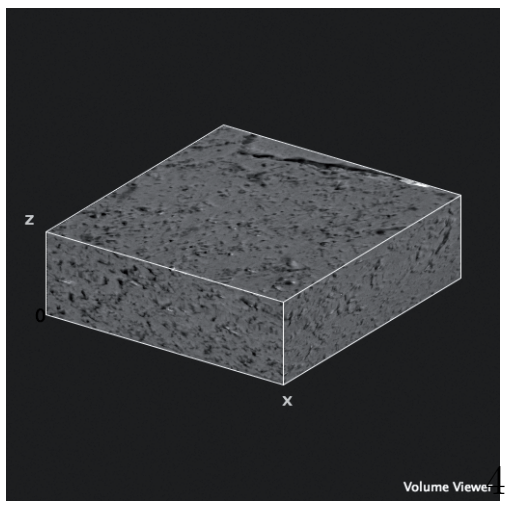

(g)

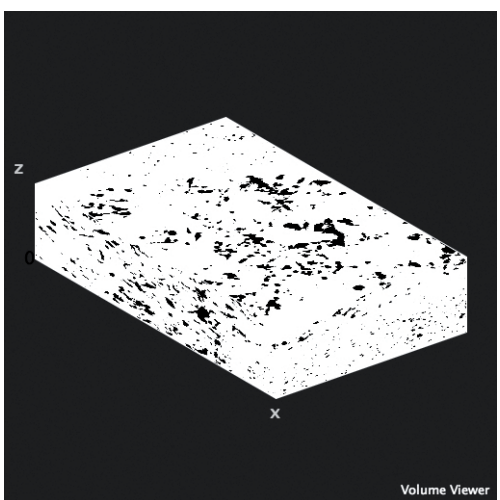

(b)

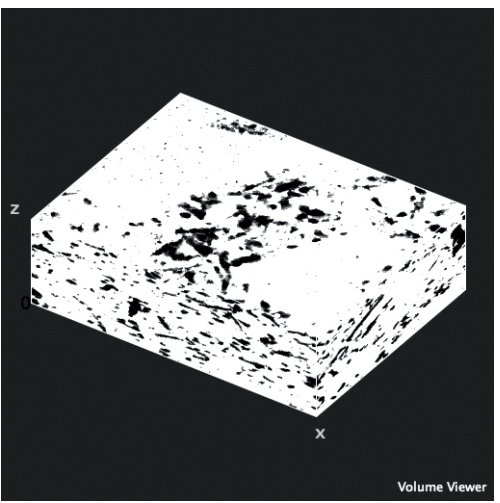

(d)

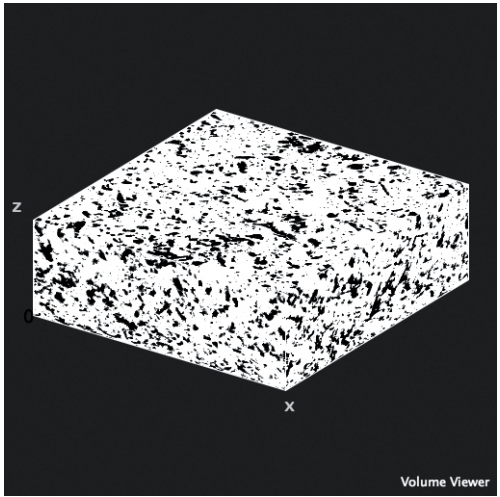

(f)

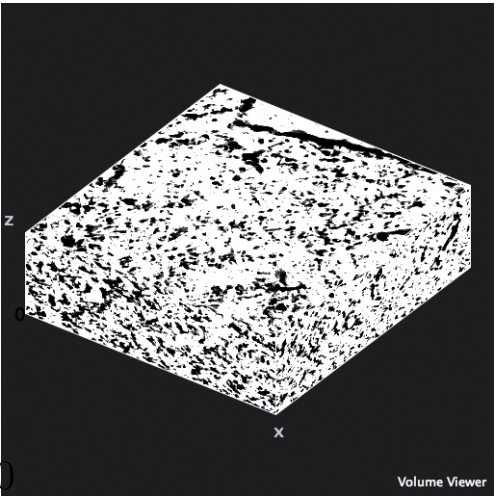

(h)

Figure 2: FIB/SEM images, before and after segmentation by the Otsu algorithm, of CEMI HPC for sample $(\mathrm{a}, \mathrm{b})$ : cement1; $(\mathrm{c}, \mathrm{d})$ : cement2, $(\mathrm{e}, \mathrm{f})$ : cement3 and $(\mathrm{g}, \mathrm{h})$ : cement4. 


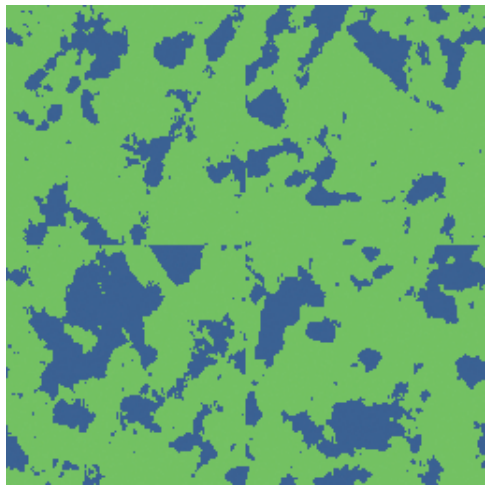

$u$

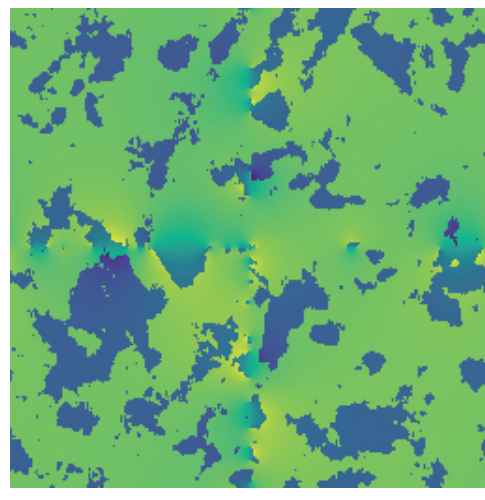

$p$

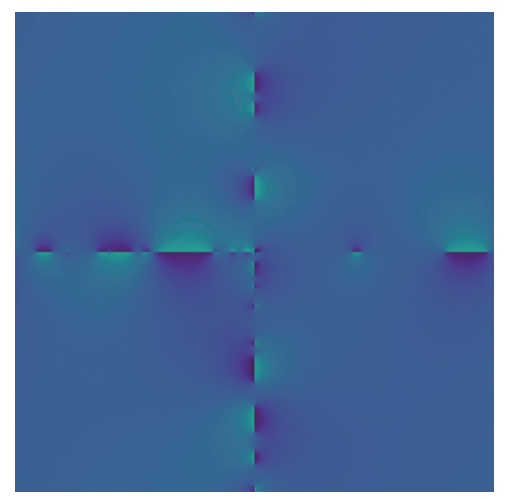

$S$

Figure 3: 'Periodic plus smooth' decomposition of a segmented image of the FIB/SEM stack cement3. The figure shows a slice $u$ of the initial image (left), as well as its periodic (middle) and smooth (right) components $p$ and $s$. For the sake of illustration, this decomposition is computed in $2 \mathrm{D}$, not $3 \mathrm{D}$, on a small, $256 \times 256$, region of interest. Besides, the four quadrants of the image have been swapped, in order to emphasize the lack of periodicity of the initial image, as indicated by the jumps along the horizontal and vertical median axes. These jumps are smeared in the periodic component $p$, while the smooth component $s$ is essentially constant far from the boundaries. The same color scale is used for all three images. 
Figure 4: 2D power spectrum of the periodic component $p$ shown in Figure 3. Computing the isotropic average of this image finally leads to the curves shown in Figure 13. 

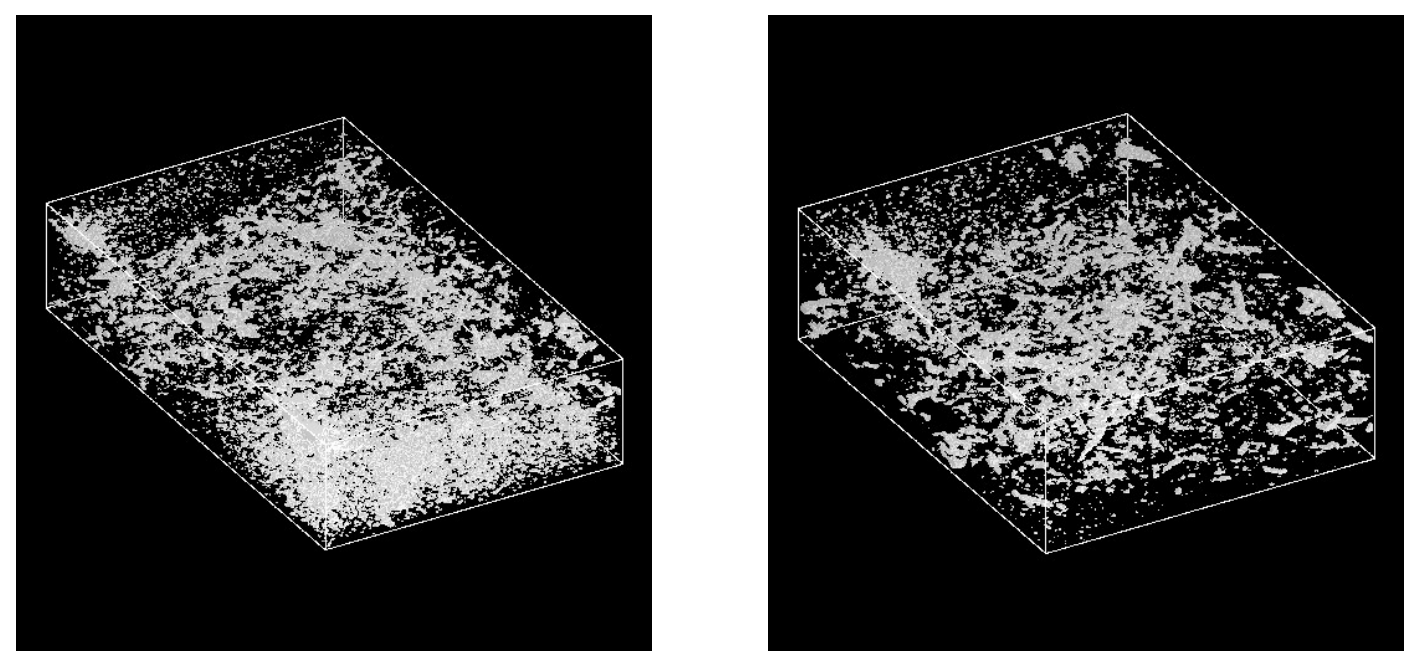

(a)

(b)
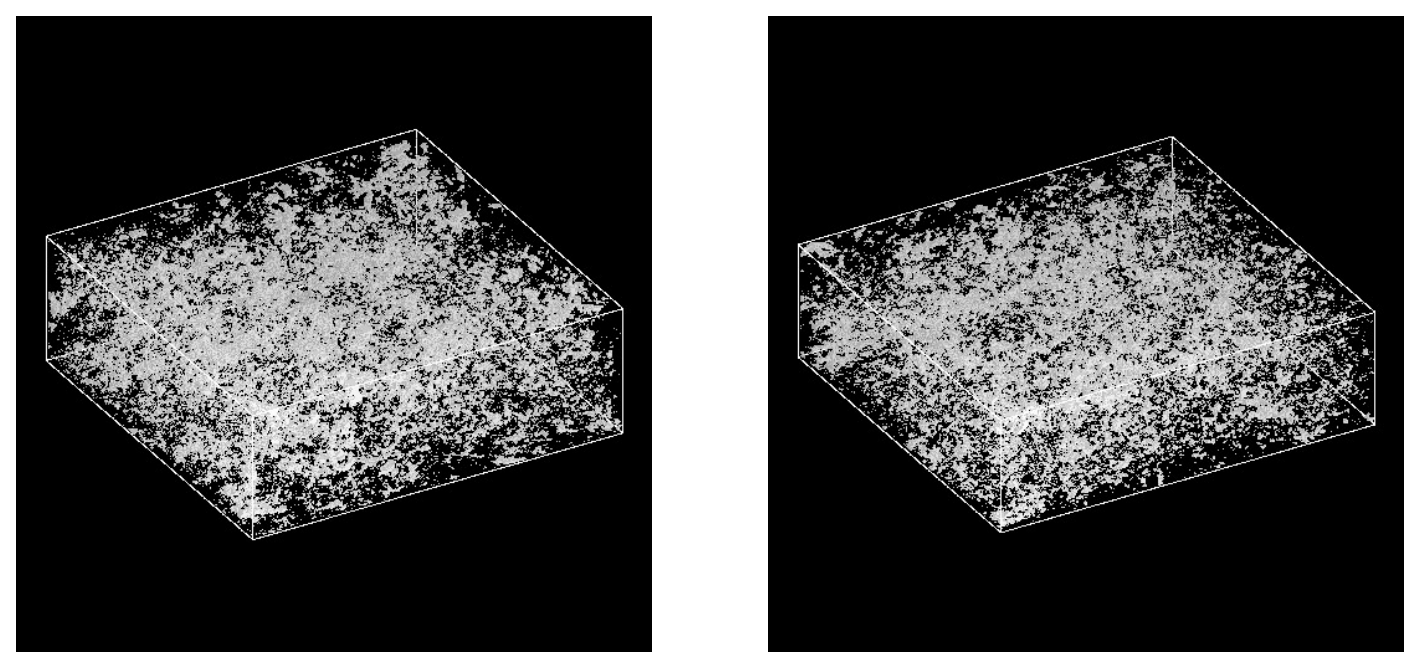

(c)

(d)

Figure 5: Isolated clusters from the FIB/SEM segmented images of CEMI HPC for sample (a): cement1; (b): cement2; (c): cement3; and (d): cement4. 

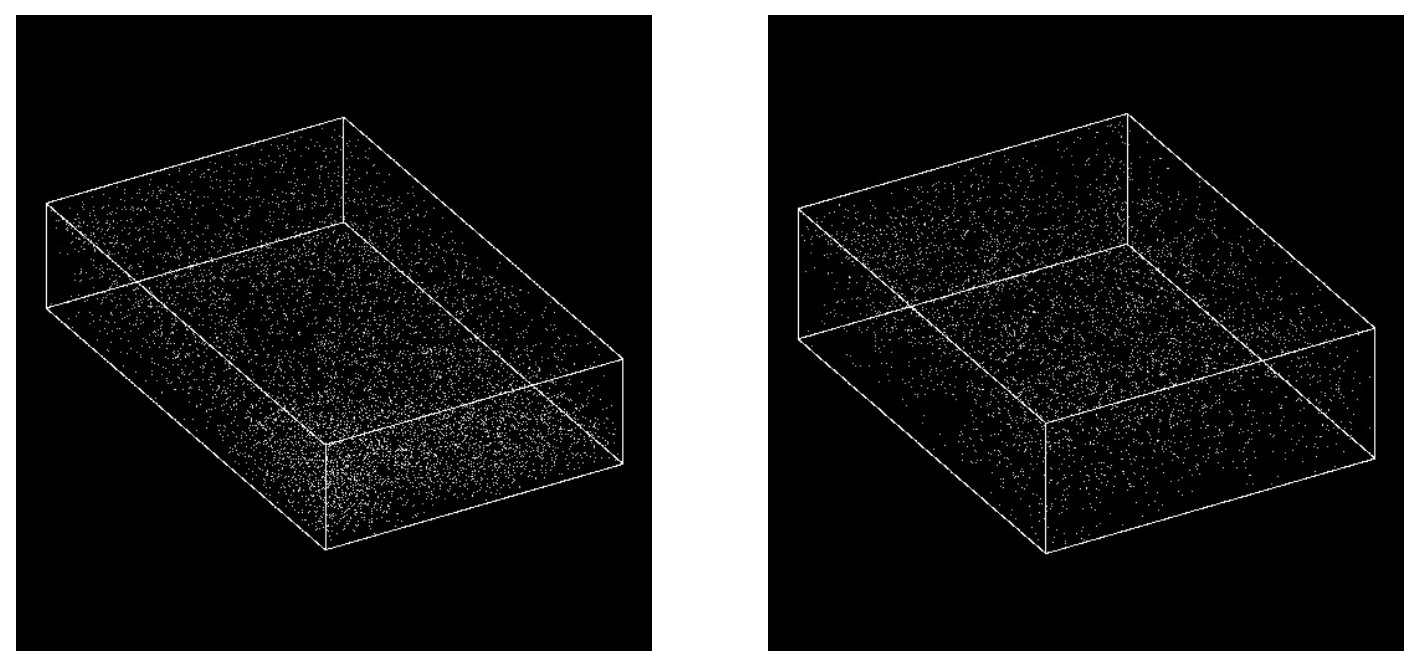

(a)

(b)
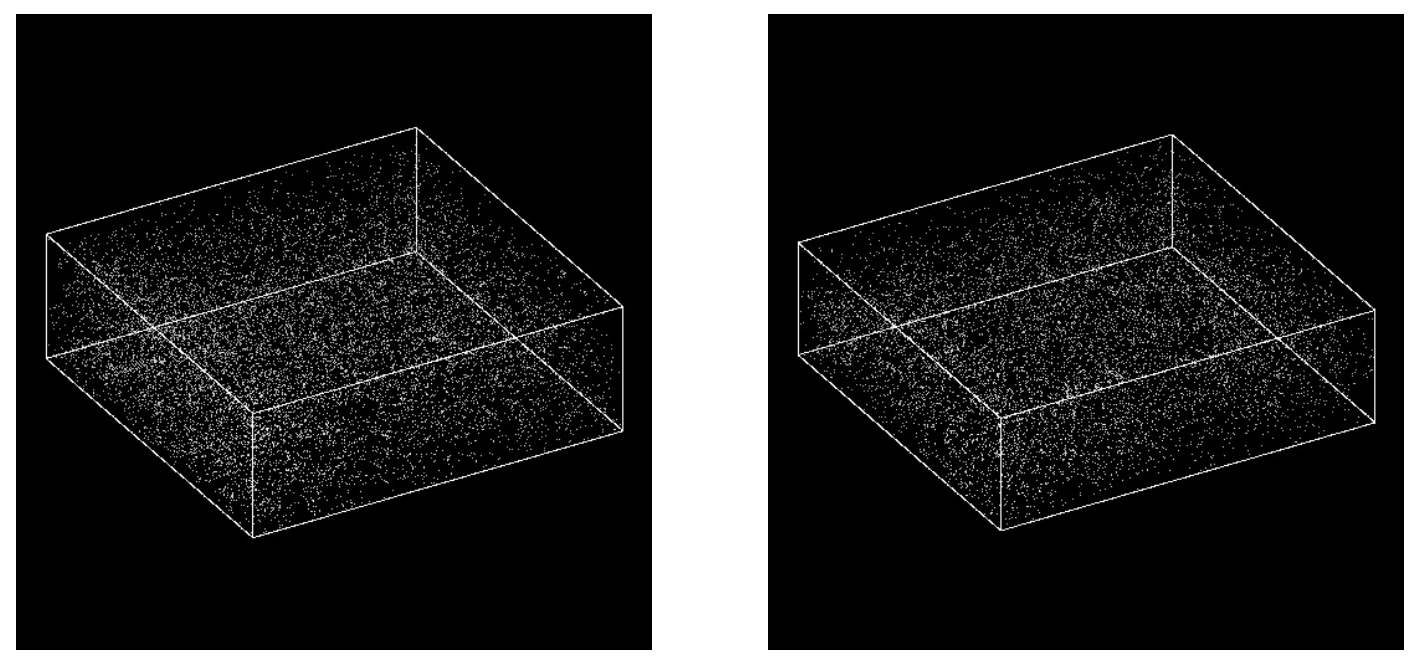

(c)

(d)

Figure 6: Isolated vertexes from the retraction graphs of the FIB/SEM segmented images of CEMI HPC for sample (a): cement1; (b): cement2; (c): cement3; and (d): cement4. 


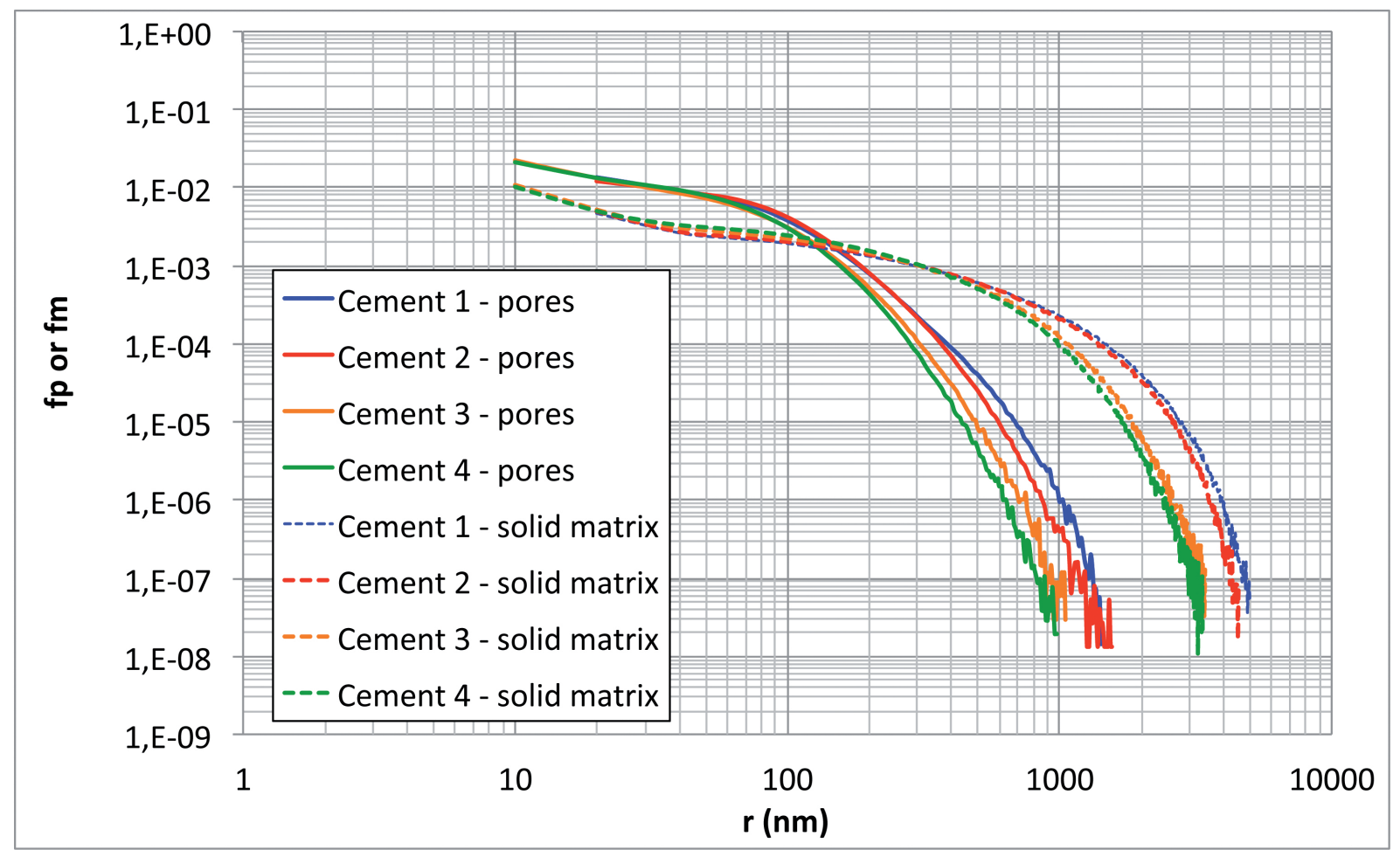

Figure 7: Chord length distributions (in a log-log diagram), obtained from the FIB/SEM segmented images of a CEMI HPC, on samples cement1, cement2, cement3 and cement4. 


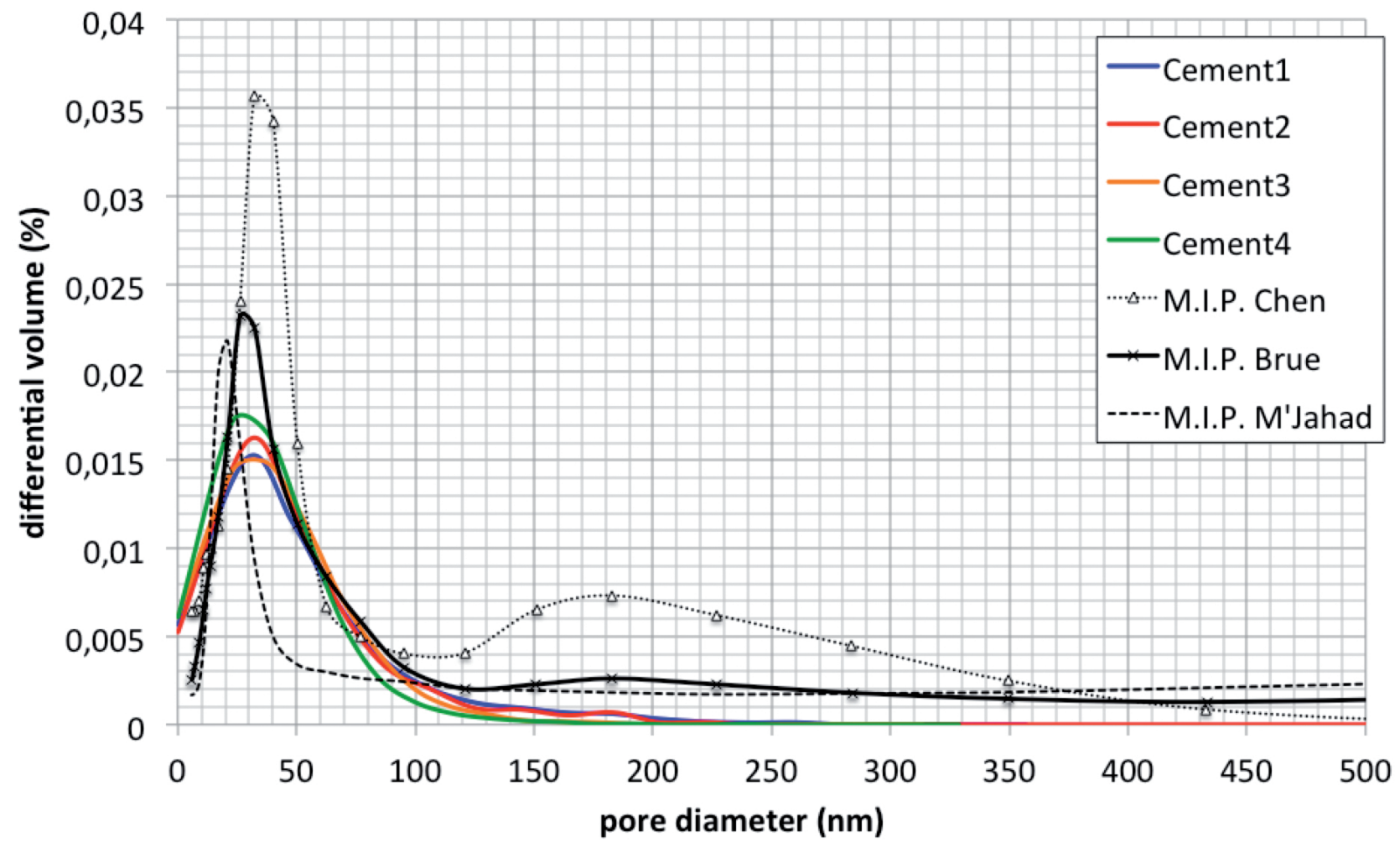

Figure 8: Pore size distributions in volume, obtained from the FIB/SEM segmented images of CEMI HPC, and compared to M.I.P. on concretes of different batches, from $[5,41 ?, 52]$. 

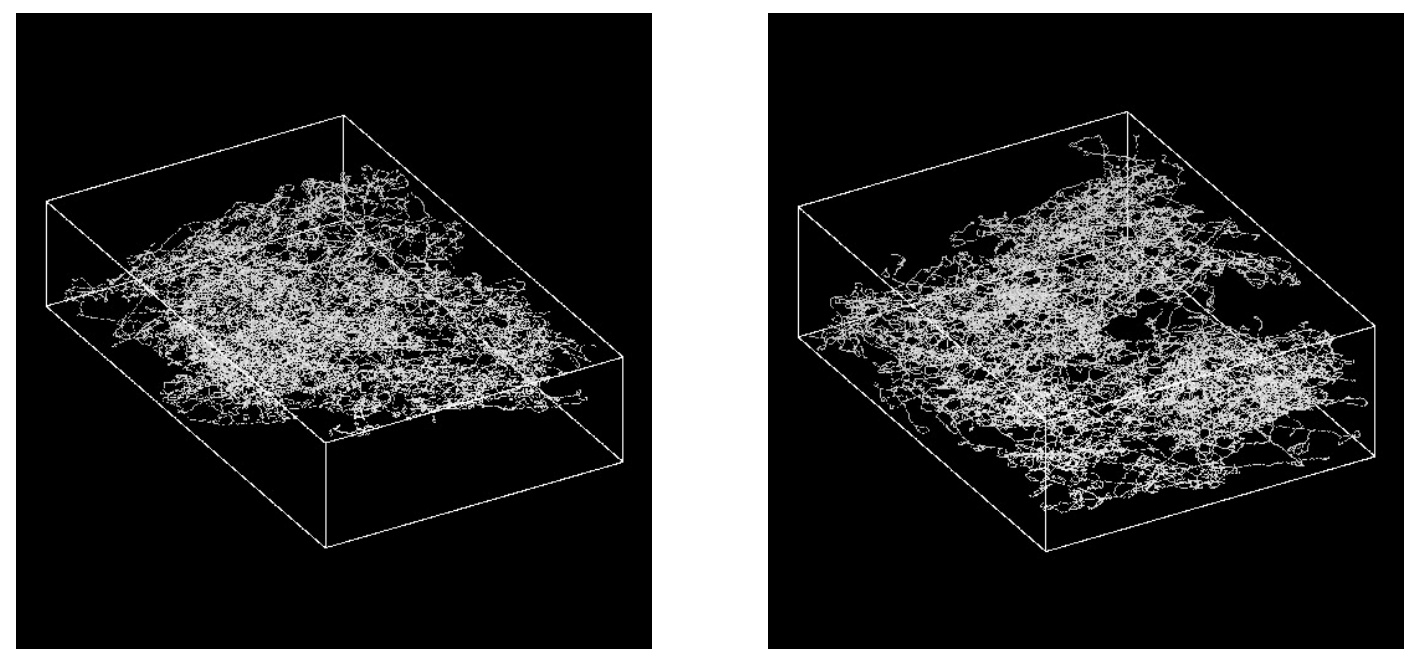

(a)

(b)
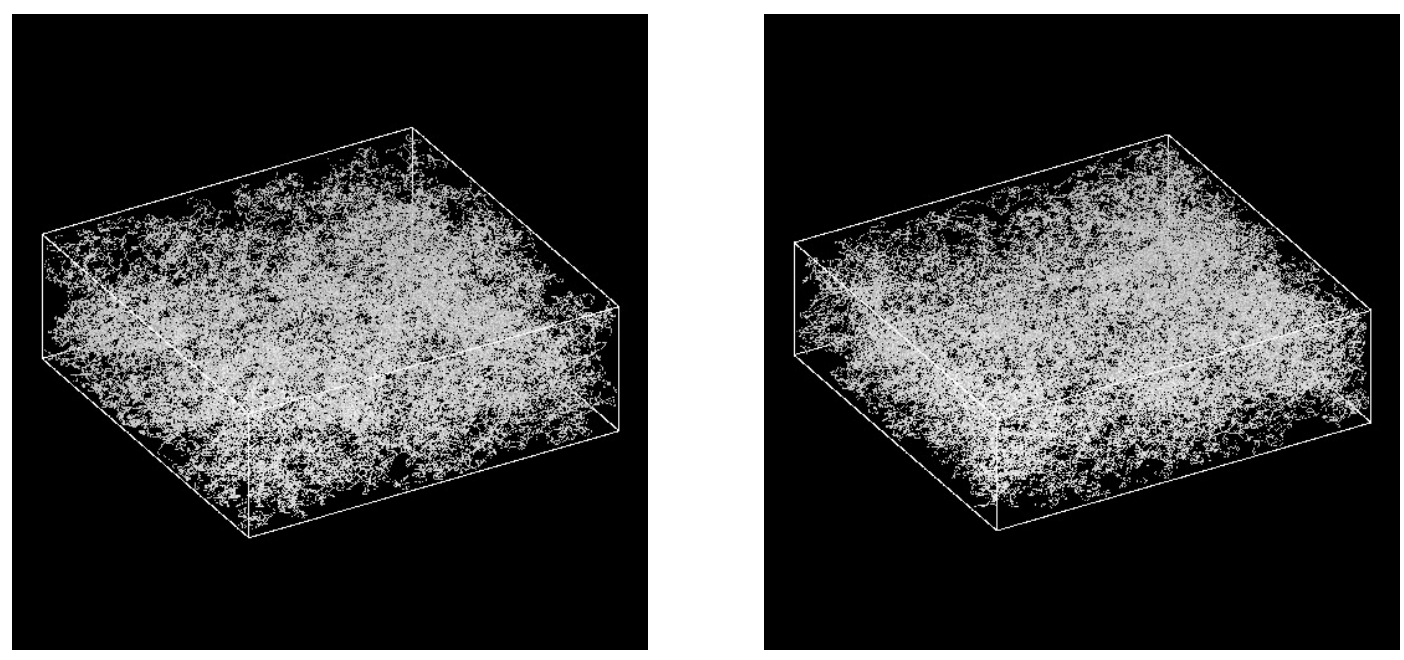

(c)

(d)

Figure 9: Retraction graphs from the FIB/SEM segmented images of CEMI HPC for sample (a): cement1; (b): cement2; (c): cement3; and (d): cement4. 

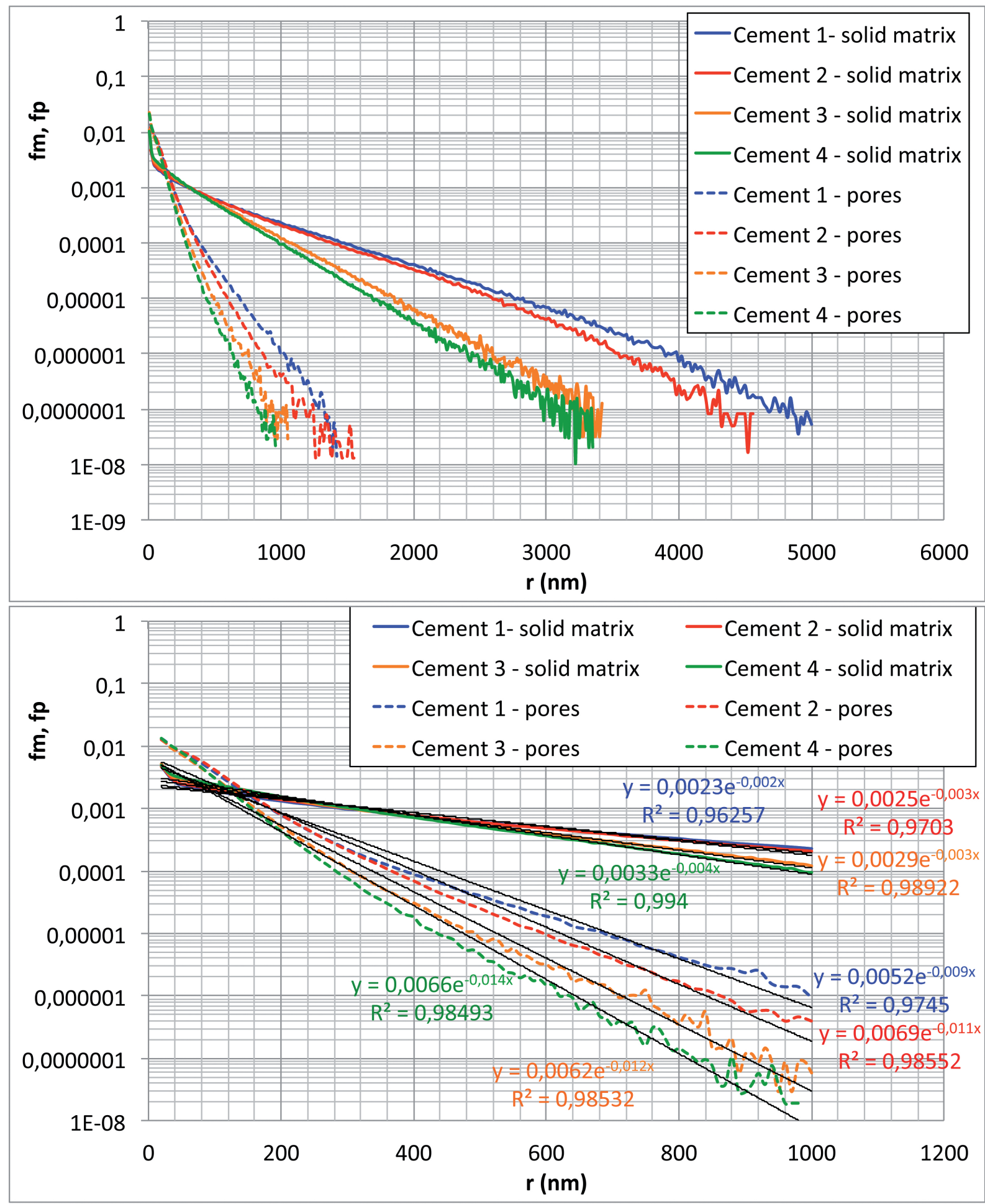

(a)

Figure 10: Chord length distributions (in a log-linear diagram), obtained from the FIB/SEM segmented images of a CEMI HPC, on samples cement1, cement2, cement3 and cement4: (a): raw data; (b): interpolation in the least squares sense on the same 20-1000nm radius $r$ range for $f_{p}(r)$ and $f_{m}\left(4_{r}^{4}\right)$. 

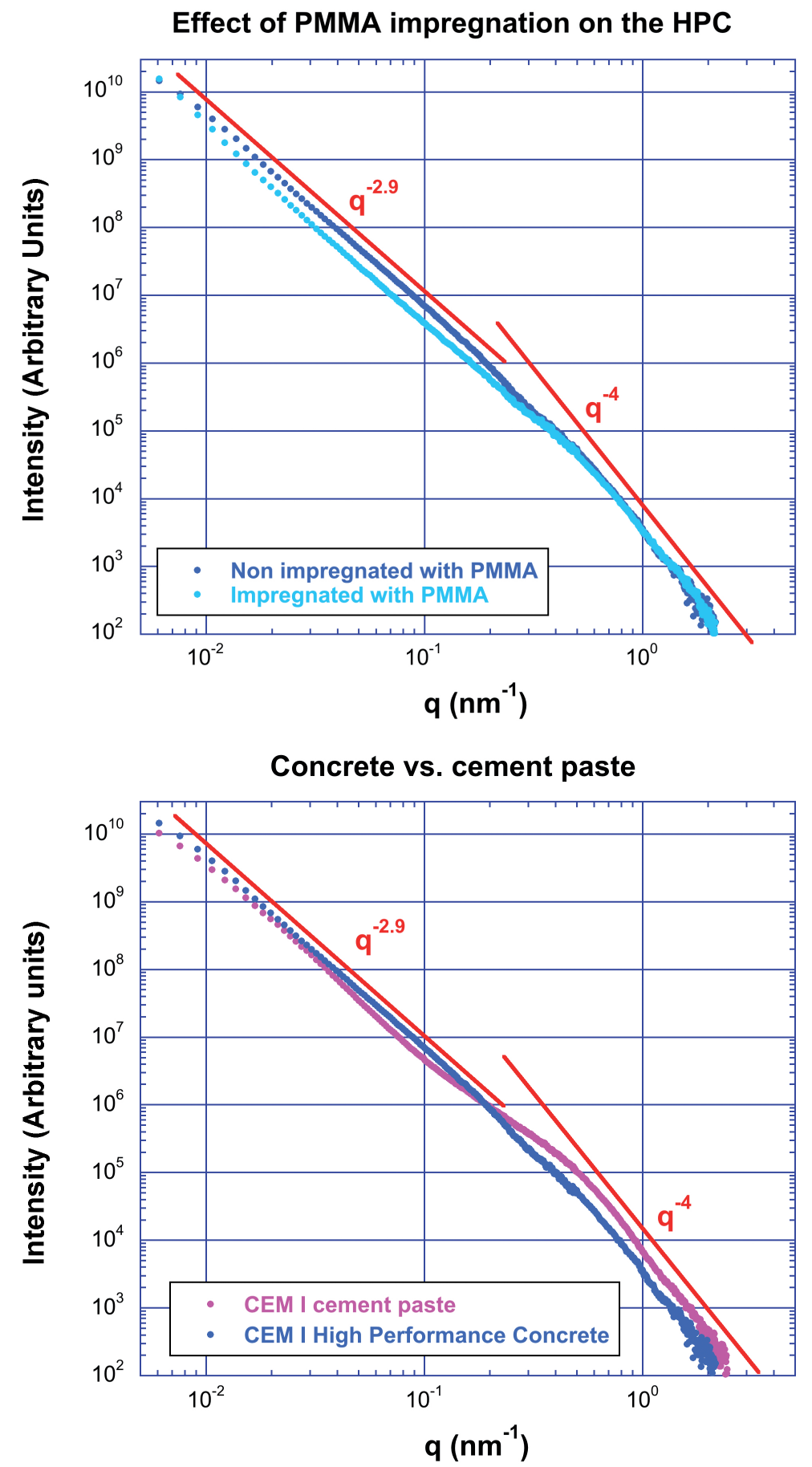

Figure 11: Experimental SAXS results on samples II and III: HPC dried at $20^{\circ} \mathrm{C}$ and stepwisely down to $30 \% R H$ for five years, (a): with and without PMMA resin-impregnation; (b): HPC dried at $20^{\circ} \mathrm{C}$ and stepwisely down to $30 \% R H$ for five years, compared to pure Portland mature cement paste dried at $20^{\circ} \mathrm{C}$ and $43 \% R H$. In (b), both samples are not impregnated with PMMA. 


\section{Effect of the drying cure}

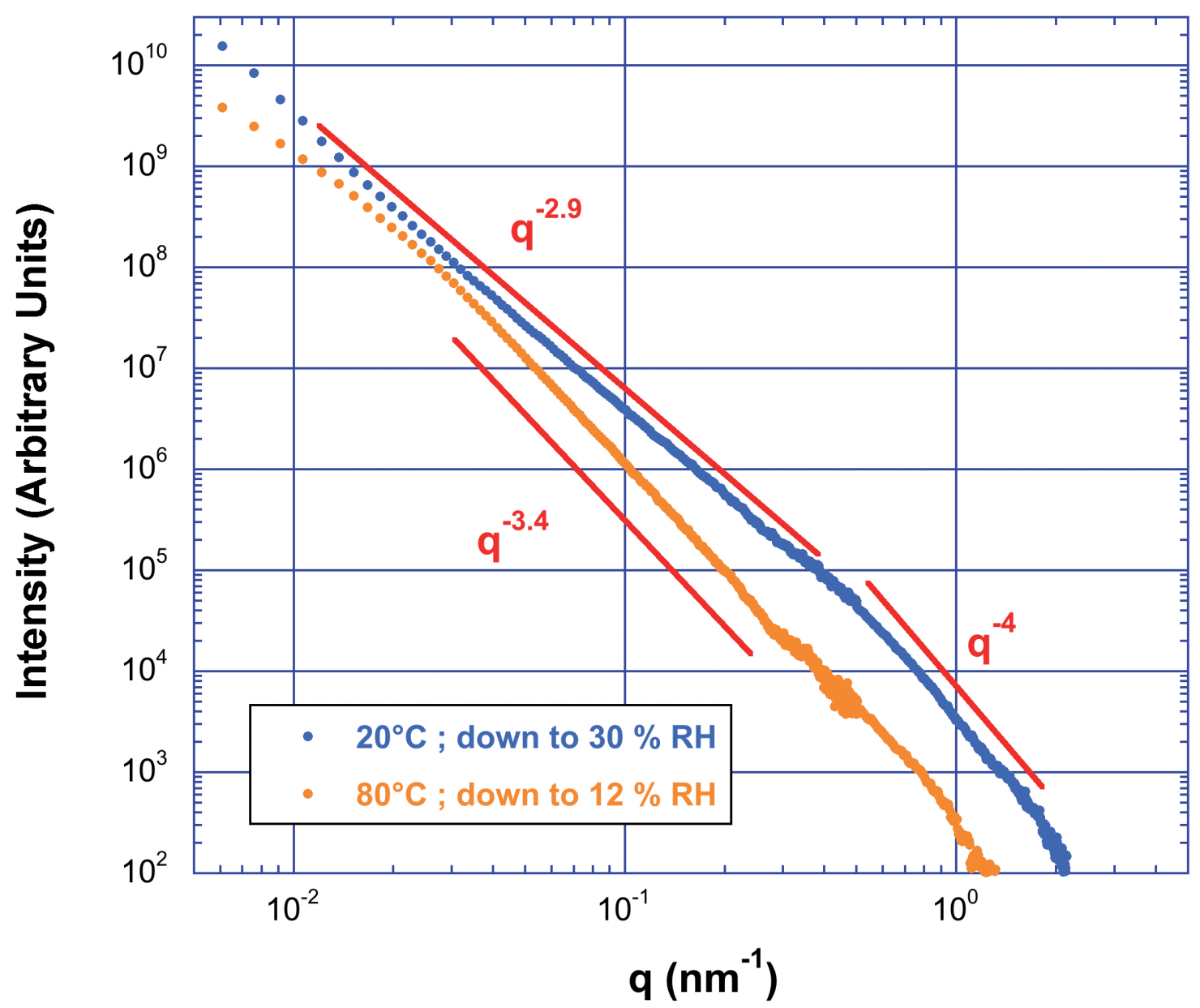

Figure 12: Experimental SAXS results on Samples II and IV: HPC dried at either $20^{\circ} \mathrm{C}$ and stepwisely down to $30 \% R H$ for five years, or at $80^{\circ} \mathrm{C}$ and stepwisely down to $12 \%$ $\mathrm{RH}$ for five years. Both samples are impregnated with PMMA. 


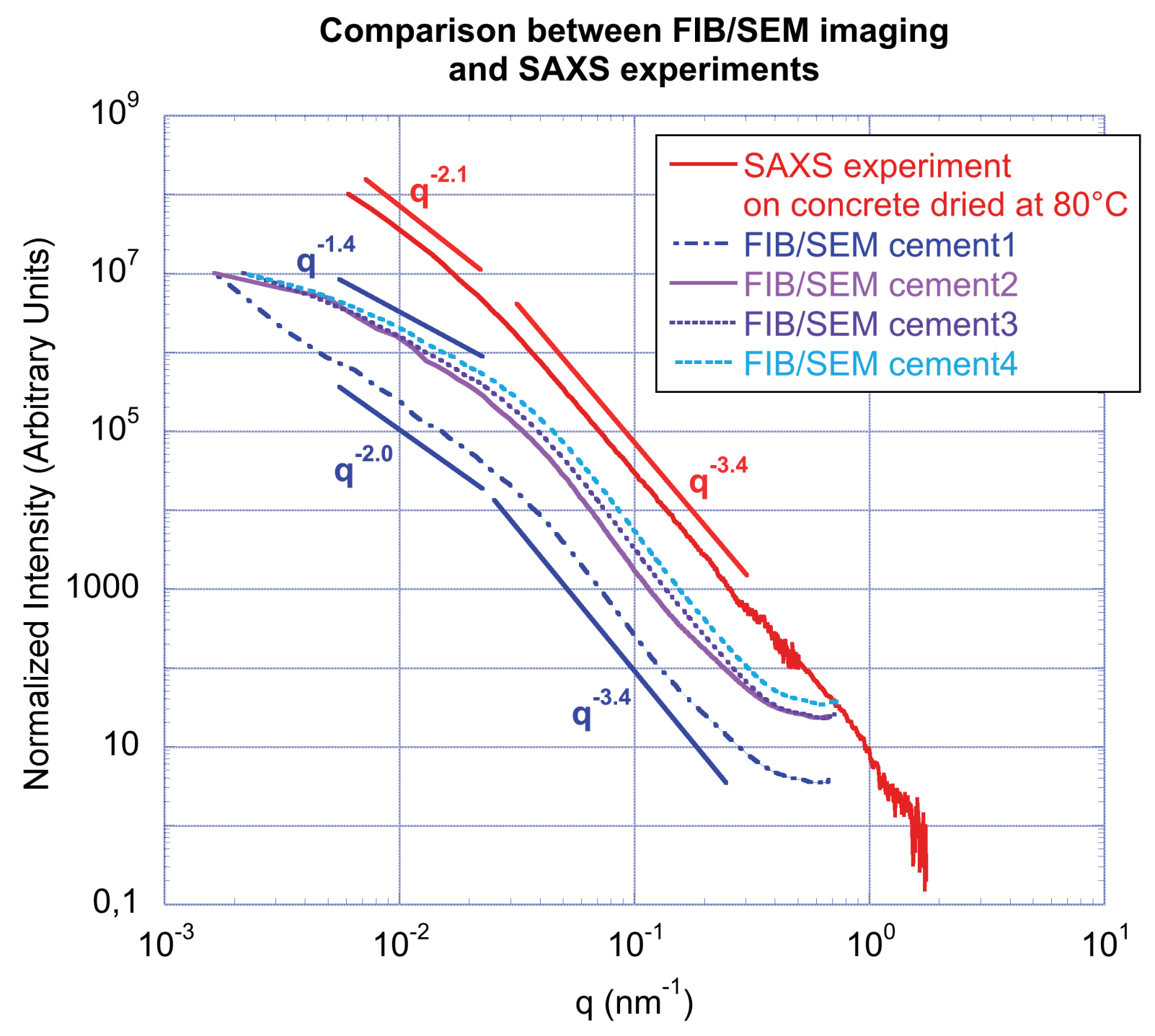

Figure 13: Comparison of $I(q)$ plots given by experimental SAXS $\left(80^{\circ} \mathrm{C} ; 12 \% R H\right)$ or by 3D numerical computations from FIB/SEM segmented images (Samples cement1, cement2, cement3 and cement4). 